\title{
ATTENUATION OF PEAK GROUND ACCELERATIONS IN NEW ZEALAND EARTHQUAKES
}

\author{
J X Zhao ${ }^{1,2}$, D J Dowrick ${ }^{1,3}$ and G H McVerry ${ }^{1,3}$
}

\begin{abstract}
SUMMARY
The main result of this study is the development of attenuation expressions for peak ground accelerations (PGAs) in New Zealand earthquakes, in terms of magnitude $M_{w}$ and shortest distance from the source. Other factors which are modelled are depth, focal mechanism, ground class and tectonic type of earthquake i.e. crustal, interface or dipping slab. As well as being implied in the source distance, the substantial effect of depth is modelled well with a separate linear depth term. For crustal events, focal mechanisms which are predominantly reverse are found to cause PGAs that are 28 percent stronger on average than for other mechanisms. PGAs at soil sites (ie those having soil deposits $>3 \mathrm{~m}$ thick) are found to be 53 percent stronger on average than at other (ie rock) sites, but the difference between PGAs on rock and soil sites in large amplitude shaking remains uncertain, ie near the source of events of $M_{w} \geq 7$. Earthquakes occurring on the interface between the Pacific and Australian tectonic plates give rise to smaller PGAs than do crustal or slab events of the same magnitude, depth and distance. Comparisons are made between our New Zealand model and some for Europe, Japan and the Western USA.
\end{abstract}

\subsection{INTRODUCTION}

It was only in 1993 that sufficient New Zealand ground motion data became available for the development of a reasonably robust attenuation model for peak ground accelerations (PGAs) in shallow New Zealand earthquakes. The first examination of local PGAs, made in 1980 [1], was based on too little data to produce adequately constrained models, while two recent studies [2,3] were deliberately restricted to examining specific earthquakes. The 1993 study [3] of the 1968 Inangahua earthquake finally established for the first time data from a large enough earthquake $\left(M_{W}\right.$ 7.2) to allow the estimation of a plausible coefficient for magnitude in a New Zealand regression expression. As a prelude to the present paper, a preliminary analysis $[4,5]$ was made at that time of a smaller data set than has been used in the present paper.

While the New Zealand data set is still too small to robustly model all of the desired aspects, it is of great importance to explore the nature and robustness of the attenuation expressions which it can now yield. Until now, reliance has been placed heavily on expressions derived for other regions of the world, but these have been shown to vary considerably $[2,6]$, and the choice of the best analogy for New Zealand is of course a moot point without adequate criteria for selection. This paper includes some comparisons with other regions, as already attempted in the other recent studies [2-5].

\footnotetext{
Institute of Geological \& Nuclear Sciences, Lower Hutt, N.Z.

2 Member

3 Fellow
}

Of the various physical factors that appear to affect the strength of ground shaking, apart from magnitude and source distance, four factors of particular interest are tectonic type, ground class, fault mechanism and depth. With New Zealand being in a subduction zone, earthquakes range in depth from shallow to very deep, occurring in the crust, on the plate interface or in the dipping slab, and a full range of fault mechanisms occur with some regional biases. Although success in evaluating the influence of these factors in other studies overseas has been mixed, the need to understand their influence is so great that we decided to attempt to address them all in this study. Another possibly important effect that we have not considered is directivity in the radiation pattern, resulting from either source effects or anisotropic attenuation.

Because of a shortage of near-source recordings in our New Zealand data set, some PGAs recorded overseas at very short source distances were used to supplement the New Zealand data base, and provide some constraint on the models at short distances. The New Zealand data included magnitudes up to $\mathrm{M}_{\mathrm{w}}$ 7.2 and distances down to $11 \mathrm{~km}$.

The functional forms of the models that we finally selected do not allow for the possibility of "saturation" of PGA values at large magnitudes. A model that we considered that did allow magnitude saturation at short distances showed little variation of the dependence on magnitude with distance. We have also assumed that the standard deviation of the scatter around the mean predicted value is constant, rather than a function of magnitude or 
amplitude. A one-stage regression analysis procedure was used throughout.

\subsection{NEW ZEALAND EARTHQUAKES STUDIED}

The New Zealand earthquakes with strong-motion data used in this study were limited to those for which both PGA data and moment magnitudes $M_{w}$ were available. Except for two events, $M_{w}$ was derived from the preferred seismic moment as discussed by Dowrick and Rhoades [7]. For two events for which no seismic moment was available (Nos 6 and 19 in Table 1), $M_{w}$ was estimated from their $M_{s}$ values using a relationship developed elsewhere [7]. These two events were included only in the analyses of residuals for examining regional effects in regions with few data, but not in the regression analyses for developing the attenuation expressions.

New Zealand's network of strong-motion recorders is relatively young, the earliest year for which reliable recorded PGAs can be ascribed to specific events being 1966. In the period of our data catchment (1966-94) we have 51 events (Table 1) for which $M_{w}$ and PGAs are available. These events range in magnitude from $M_{w} 5.08$ to $M_{w} 7.23$. The latter value is for the 1968 Inangahua earthquake, and lies between the published $M_{w}$ of 7.1 [8] and $M_{s}$ of 7.4 [7]. As adopted elsewhere [7], we chose to include an arguable third subevent (T. Webb, pers. comm., 1993) which increases the moment by $60 \%$ and results in $\mathrm{M}_{\mathrm{w}}=7.23$. Note that while we used $M_{w}$ values to two decimal places in the analysis, in the text we mostly use $M_{w}$ values rounded to the conventional one decimal place.

As seen in Figure 1, the events are mainly distributed along the eastern part of the North Island and the western part of the South Island, which are regions close to the subduction zones along the boundary between the Pacific and Australian tectonic plates. Because of the presence of the subducting plates, large magnitude events occur down to considerable depths under New Zealand (Figure 2), the deepest event in our data set having a depth of 149 $\mathrm{km}$ and a magnitude $\mathrm{M}_{\mathrm{w}}$ 6.6. Of the 51 events in our data set, only nine have depths greater than $50 \mathrm{~km}$, all nine occurring in the dipping slabs of the subducting Pacific or Australian plates. The remaining 42 shallower events have depths ranging from 4 to 41 $\mathrm{km}$. Sixteen of these events have depths $>20 \mathrm{~km}$, and all but two of these are in the North Island on the interface or in the dipping slab (Figure 1). As our measure of depth we use the depth to the centroid of the rupture, rather than the traditional focal depth. We consider the centroid to give a better physical representation of the centre of energy release and hence to be a better measure of earthquake "depth" per se than the focal depth.

Regarding tectonic type, in the New Zealand data set there are 24 crustal events, 7 interface events and 20 dipping slab events, denoted $\mathrm{C}, \mathrm{I}$ and $\mathrm{S}$ respectively in Table 1.

The predominant source mechanism for each event, as given in Table 1 and Figure 2, is labelled normal $(\mathrm{N})$, strike-slip (S) or reverse (R). Most mechanisms are of course not pure N, S or R; therefore where for example a mechanism is partly $R$ and partly $S$, we define it as predominantly $\mathrm{R}$ if the ratio of the components $\mathrm{R} / \mathrm{S}$ $\geq 1.0$. Considering only those events of depth $<50 \mathrm{~km}$, there are 16 reverse, 9 strike-slip, and 17 normal mechanisms. Twelve of the 26 events with depths $\leq 20 \mathrm{~km}$ have reverse mechanisms, while of the 14 events of depth $21-50 \mathrm{~km}$ only interface events have reverse mechanisms.
Source parameter data in Table 1 incorporate the best quality information, derived from special studies where available, as referenced in Table 1.

\subsection{NEW ZEALAND GROUND MOTION DATA}

From the 51 New Zealand events a total of 461 strong-motion records were available, at horizontal distances from the source ranging from $11 \mathrm{~km}$ to $573 \mathrm{~km}$. Peak ground accelerations were obtained from digital, mechanical-optical, and scratch plate instruments, located either on the ground or in the bases of buildings. A plot of the data in terms of $M_{w}$ against $\log _{10}$ of shortest distance to the source is given in Figure 3.

The New Zealand PGAs used in this study are listed in computer file NZPGA.ZDM; this file is available from the authors at IGNS, Lower Hutt. The data comprises PGAs in two horizontal directions for each record, namely along the instrument axes for time-based accelerographs, and NS and EW components for the scratch plate instruments. Vertical accelerations are also included where available. The largest horizontal acceleration in our New Zealand data set is $0.58 \mathrm{~g}$ recorded on a scratch plate in the $\mathrm{M}_{\mathrm{w}} 7.2$ 1968 Inangahua earthquake at Reefton $15 \mathrm{~km}$ from the closest point on the preferred source model [3]. The second largest horizontal PGA is $0.46 \mathrm{~g}$ recorded on a digital accelerograph in the $M_{w} 6.81994$ Arthur's Pass earthquake. The largest vertical acceleration is $0.38 \mathrm{~g}$, and also was recorded at Arthur's Pass Police Station in 1994.

The distance of each PGA observation was measured as the shortest distance to the source. For those ten New Zealand events where a model of the rupture surface was available, the slant distance from the recording site to the closest point on the rupture surface was taken. The fault rupture geometry adopted for this purpose is given in Table 2. For each remaining event the slant distance to its centroid was taken, i.e. to the centroid of the rupture surface. Most of this second type of distance data is not sensitive to the use of the centroid compared with the closest point on the rupture surface, as the dimensions of most of the rupture surfaces would have been relatively small compared to the slant distances. In only five instances was this discrepancy likely to have been more than 10 percent. The depth used here is the "centroid depth" $\left(h_{c}\right)$ called the "effective depth" in previous papers $[2,3]$.

The "centroid depth" is the standard depth determined in focal mechanism and moment determinations [e.g. References 7,9,11]. In 23 cases the centroid depths as determined in local focal mechanism studies $[8,9,12]$ were adopted, and a further seven (for Events Nos 18, 28-32, 43, 51) came from aftershock studies [13-15]. For 10 earthquakes (Events 14-19, 35-37,39) depths were assigned using data from the ISC, as advised by T.H. Webb [10]. For the remaining 10 events, the depths were estimated [mostly in Ref. 7] considering all available information, i.e. the Harvard [11] centroid depth, the locally determined focal depth [10], and the seismogenic depth range at the epicentre.

The minimum value of PGA that was accepted for use in this study depended on the resolution of the instrument on which each recording was made. The smallest values considered to be sufficiently accurate were:

- $\quad$ acceleroscopes (scratch-plates): $0.02 \mathrm{~g}$

- mechanical-optical: $0.01 \mathrm{~g}$ (horizontal), $0.005 \mathrm{~g}$ (vertical) 
Table 1: New Zealand earthquakes considered in this study

\begin{tabular}{|c|c|c|c|c|c|c|c|c|c|c|c|c|}
\hline \multirow[b]{2}{*}{ No. } & \multirow[b]{2}{*}{$\mathrm{yr}$} & \multicolumn{2}{|c|}{ Date } & \multirow{2}{*}{$\begin{array}{c}\text { UT } \\
\mathrm{hr} / \mathrm{min}\end{array}$} & \multicolumn{2}{|c|}{ Epicentre } & \multirow[t]{2}{*}{$\mathrm{M}_{\mathrm{w}}$} & \multirow{2}{*}{$\begin{array}{l}\text { Centroid } \\
\text { depth } \\
(\mathrm{km})\end{array}$} & \multirow{2}{*}{$\begin{array}{l}\text { Tect. } \\
\text { Type }\end{array}$} & \multirow{2}{*}{$\begin{array}{l}\text { Predom } \\
\text { Source } \\
\text { Mech. }\end{array}$} & \multirow[b]{2}{*}{ Region } & \multirow[b]{2}{*}{ Refs. } \\
\hline & & mo & dy & & ${ }^{0} \mathrm{~S}$ & ${ }^{\circ} \mathrm{E}$ & & & & & & \\
\hline 1 & 1966 & 03 & 04 & 2358 & 38.45 & 177.91 & 5.64 & 24 & I & $\mathrm{R}$ & & 8 \\
\hline 2 & 1966 & 04 & 23 & 0649 & 41.63 & 174.40 & 5.75 & 19 & $\mathrm{C}$ & $\mathrm{R}$ & & 8 \\
\hline $3 \nabla$ & 1968 & 05 & 23 & 1724 & 41.76 & 171.96 & 7.23 & 10 & $\mathrm{C}$ & $\mathrm{R}$ & & 8 \\
\hline 4 & 1968 & 09 & 25 & 0702 & 46.49 & 166.68 & 6.27 & 4 & $\mathrm{C}$ & $\mathrm{S}$ & & 8 \\
\hline 5 & 1971 & 08 & 13 & 1442 & 42.13 & 172.10 & 5.70 & 9 & $\mathrm{C}$ & S & & 8 \\
\hline 6 & 1972 & 01 & 08 & 2133 & 37.57 & 175.69 & $5.27 \dagger$ & 7 & $\mathrm{C}$ & $\mathrm{N}$ & & 7,10 \\
\hline 7 & 1973 & 01 & 05 & 1354 & 39.04 & 175.25 & 6.57 & 149 & $S$ & $\mathrm{R}$ & & 9 \\
\hline 8 & 1974 & 11 & 05 & 1038 & 39.65 & 173.63 & 5.44 & 17 & $\mathrm{C}$ & $\mathrm{N}$ & & 9 \\
\hline 9 & 1975 & 06 & 10 & 1011 & 40.34 & 175.93 & 5.62 & 38 & $\mathrm{~S}$ & $\mathrm{~N}$ & & 9 \\
\hline 10 & 1976 & 05 & 04 & 1356 & 44.67 & 167.45 & 6.51 & 10 & $\mathrm{C}$ & $R$ & $F^{(1)}$ & 8 \\
\hline 11 & 1977 & 01 & 18 & 0541 & 41.73 & 174.30 & 6.02 & 34 & S & $\mathrm{N}$ & & 9 \\
\hline 12 & 1977 & 05 & 11 & 0241 & 43.26 & 171.73 & 5.20 & 10 & $\mathrm{C}$ & $\mathrm{S}$ & & 11 \\
\hline 13 & 1979 & 03 & 24 & 2106 & 41.94 & 171.63 & 5.08 & 10 & C & $\mathrm{R}$ & & 11 \\
\hline 14 & 1980 & 06 & 23 & 1645 & 39.90 & 175.60 & 5.49 & 61 & $S$ & $\mathrm{R}$ & & 10,11 \\
\hline 15 & 1980 & 10 & 05 & 1532 & 39.70 & 176.82 & 5.66 & 36 & S & $\mathrm{N}$ & & 10,11 \\
\hline 16 & 1980 & 11 & 25 & 0457 & 37.78 & 178.97 & 5.54 & 41 & $S$ & $\mathrm{~N}$ & & 10,11 \\
\hline 17 & 1982 & 02 & 05 & 1751 & 40.64 & 175.92 & 5.36 & 34 & $S$ & $\mathrm{~N}$ & & \\
\hline 18 & 1982 & 09 & 02 & 1558 & 39.74 & 176.93 & 5.46 & 31 & $S$ & $\mathrm{~N}$ & & 10,11 \\
\hline 19 & 1984 & 03 & 05 & 0207 & 38.92 & 175.78 & $5.27 \dagger$ & 9 & C & $\mathrm{N}$ & $\mathrm{V}^{(2)}$ & 7,10 \\
\hline 20 & 1984 & 03 & 08 & 0040 & 38.31 & 177.29 & 5.91 & 80 & $S$ & $\mathrm{R}$ & & 9 \\
\hline 21 & 1984 & 06 & 24 & 1329 & 43.60 & 170.56 & 6.14 & 13 & $\mathrm{C}$ & S & & 8 \\
\hline 22 & 1985 & 07 & 19 & 1433 & 38.72 & 177.30 & 5.92 & 31 & $\mathrm{~S}$ & $\mathrm{~N}$ & & 9 \\
\hline $23 \nabla$ & 1987 & 03 & 02 & 0142 & 37.88 & 176.84 & 6.53 & 6 & $\mathrm{C}$ & $\mathrm{N}$ & & 9 \\
\hline 24 & 1988 & 06 & 03 & 2327 & 45.10 & 167.17 & 6.69 & 60 & S & $\mathrm{R}$ & $\mathrm{F}$ & 8 \\
\hline 25 & 1989 & 05 & 31 & 0554 & 45.27 & 166.88 & 6.33 & 24 & I & $S$ & $\mathrm{~F}$ & 8 \\
\hline 26 & 1989 & 08 & 08 & 0759 & 40.12 & 174.30 & 5.40 & 112 & $S$ & $\mathrm{R}$ & & 9 \\
\hline $27 \nabla$ & 1990 & 02 & 10 & 0327 & 42.32 & 172.74 & 5.93 & 8 & C & $S$ & & 8 \\
\hline $28 \nabla$ & 1990 & 02 & 19 & 0534 & 40.38 & 176.22 & 6.23 & 27 & $S$ & $\mathrm{~N}$ & & 9,13 \\
\hline $29 \nabla$ & 1990 & 05 & 13 & 0423 & 40.35 & 176.23 & 6.37 & 13 & C & $\mathrm{R}$ & & 9,13 \\
\hline 30 & 1990 & 08 & 15 & 1554 & 40.32 & 176.44 & 5.17 & 28 & $S$ & $\mathrm{~N}$ & & 11,13 \\
\hline 31 & 1990 & 10 & 04 & 2348 & 41.60 & 175.41 & 5.57 & 15 & 1 & $\mathrm{R}$ & & 11,14 \\
\hline 32 & 1990 & 10 & 06 & 0241 & 41.60 & 175.41 & 5.46 & 15 & I & $\mathrm{R}$ & & 11,14 \\
\hline 33 & 1991 & 01 & 28 & 1258 & 41.89 & 171.58 & 5.79 & 10 & C & $\mathrm{R}$ & & 8 \\
\hline 34 & 1991 & 01 & 28. & 1800 & 41.90 & 171.67 & 5.93 & 11 & $\mathrm{C}$ & $\mathrm{R}$ & & 8 \\
\hline 35 & 1991 & 02 & 15 & 1048 & 42.04 & 171.59 & 5.42 & 9 & C & $\mathrm{R}$ & & 10,11 \\
\hline 36 & 1991 & 07 & 12 & 0442 & 39.31 & 175.97 & 5.30 & 69 & $S$ & $S$ & & 10,11 \\
\hline 37 & 1991 & 09 & 08 & 1350 & 40.25 & 175.17 & 5.61 & 94 & $S$ & $\mathrm{R}$ & & 10,11 \\
\hline 38 & 1992 & 03 & 02 & 0905 & 40.31 & 176.48 & 5.54 & 26 & $S$ & $\mathrm{~N}$ & & 11,13 \\
\hline 39 & 1992 & 03 & 30 & 0702 & 43.05 & 171.23 & 5.50 & 5 & $\mathrm{C}$ & $\mathrm{R}$ & & 10,11 \\
\hline 40 & 1992 & 05 & 16 & 1757 & 38.23 & 178.37 & 5.76 & 22 & I & $\mathrm{R}$ & & 11 \\
\hline 41 & 1992 & 05 & 27 & 2230 & 41.63 & 173.62 & 5.88 & 67 & $S$ & $S$ & & 9 \\
\hline 42 & 1992 & 06 & 21 & 1743 & 37.67 & 176.86 & 6.25 & 4 & $\mathrm{C}$ & $\mathrm{N}$ & V & 9 \\
\hline $43 \nabla$ & 1993 & 04 & 11 & 0659 & 39.74 & 176.52 & 5.63 & 24 & I & $\mathrm{R}$ & & 9,15 \\
\hline $44 \nabla$ & 1993 & 08 & 10 & 0051 & 45.21 & 166.71 & 6.81 & 22 & I & $\mathrm{R}$ & $\mathrm{F}$ & 12 \\
\hline $45 \nabla$ & 1993 & 08 & 10 & 0946 & 38.52 & 177.87 & 6.19 & 39 & $\mathrm{~S}$ & $S$ & & 9 \\
\hline $46 \nabla$ & 1994 & 06 & 18 & 0325 & 43.01 & 171.46 & 6.81 & 4 & $\mathrm{C}$ & $\mathrm{R}$ & & 12 \\
\hline 47 & 1994 & 12 & 15 & 1120 & 37.27 & 177.53 & 6.31 & 12 & C & S & V & 10,11 \\
\hline 48 & 1995 & 02 & 05 & 2251 & 37.65 & 179.49 & 7.09 & 10 & C & $\mathrm{N}$ & & 10,11 \\
\hline 49 & 1995 & 02 & 10 & 0145 & 37.92 & 179.51 & 6.49 & 10 & $\mathrm{C}$ & $\mathrm{N}$ & & 10,11 \\
\hline 50 & 1995 & 03 & 22 & 1943 & 41.05 & 174.18 & 5.83 & 90 & $\mathrm{~S}$ & $S$ & & 10,11 \\
\hline 518 & 1995 & 11 & 24 & 0619 & 42.98 & 171.8 & 6.24 & 5 & $\mathrm{C}$ & $\mathrm{S}$ & & 12 \\
\hline
\end{tabular}

$\nabla$ Distances measured from nearest part of source (rupture surface)

$\dagger M_{w}$ inferred from $M_{s}$ (see text)

(1) $\mathrm{F}=$ Event located in Fiordland

(2) $\mathrm{V}=$ Event with travel paths in the Central Volcanic Region

Tectonic type: $\mathrm{C}=$ Crustal, $\mathrm{I}=$ Interface, $\mathrm{S}=$ Slab

Source mechanism: $N=$ Normal, $R=$ Reverse, $S=$ Strike-slip 


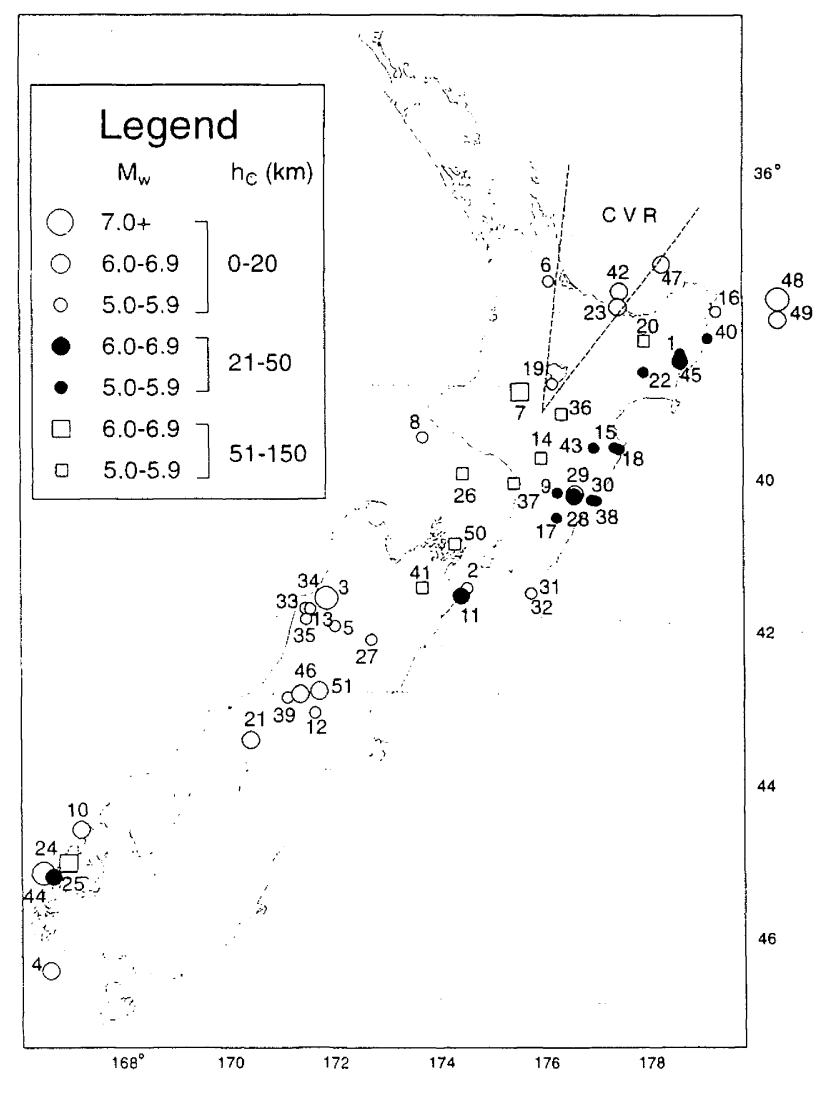

FIGURE 1 Map of locations of New Zealand earthquakes considered in this study. The Central Volcanic Region (CVR) is marked.

- $\quad$ digital (12 bit): $0.004 \mathrm{~g}$ (horizontal and vertical)

- digital (16 bit): $0.0005 \mathrm{~g}$ (horizontal and vertical)

The data was reviewed to find sites which might be subject to excessive amplification of PGA. The only site excluded for this reason was Atene A which is at the top of a steep conical hill, and exhibits strong topographical effects [16]. The six records available from that site have a mean residual in $\log _{10}$ PGA of 0.51 , corresponding to a factor of 3.2 for the PGA, and their PGAs are different from the values predicted by the attenuation expressions developed from the other records at a significance level of 0.01 .

PGA data from very deep events were restricted to those in which travel paths from source to site through solid slab or crustal rock were possible, i.e. data involving travel paths passing through the highly attenuating mantle were excluded.

\subsection{GROUND CLASSES}

New Zealand's strong-motion recorder sites have been classified into three ground classes $\mathrm{A}, \mathrm{B}$ and $\mathrm{C}$ according to the criteria given in the New Zealand loadings code [17], where Ground Class A nominally corresponds to rock or very stiff soil sites with natural periods less than $0.25 \mathrm{~s}$, Ground Class B corresponds to intermediate soil sites, and Ground Class C corresponds to flexible or deep soil sites with natural period greater than 0.6s. The code gives depths of various materials likely to produce these periods.

For the purposes of the present and other studies, the site conditions have been classified into various sub-classes according to the thickness and average shear wave velocity of soil layers, and the possibility of topographic effects [18]. As explained later, the only sub-classes affecting the outcome of this study were those relating to Class $\mathrm{A}$, defined as follows:
$\mathrm{AR}=$ Rock outcrop;
$\mathrm{AV}=$ Soil layer of thickness $\leq 3$ metres overlying
$\mathrm{AL}=\quad \begin{aligned} & \text { bedrock; } \\ & \text { Soil layer of thickness }>3 \text { metres overlying } \\ & \text { bedrock, with estimated site period less than } 0.25 \mathrm{~s} ;\end{aligned}$
$\mathrm{AT}=$ Sites conforming to subclasses $\mathrm{A}$ or $\mathrm{AV}$, and also possibly subject to topographical amplification.

\subsection{SUPPLEMENTARY OVERSEAS DATA}

New Zealand near-source recordings are as yet sparse, the shortest source distance available so far being $11 \mathrm{~km}$. In an effort to obtain an attenuation model that would give reasonable predictions of near-source PGAs, the New Zealand data were supplemented by near-source data recorded overseas. The overseas data were restricted to records from sites with source distances of $10 \mathrm{~km}$ or less. This separates the local and overseas data in distance terms, there being no overlap in the distance ranges of the two data subsets (Figure 3). It will be shown later that the overseas data have no significant influence on the model in the distance range of the New Zealand data.

The overseas data were used to constrain the model predictions at short source-to-site distances. When only the New Zealand data are used in the regression, selecting a different value of $d$ in Equation (2) will cause a very large change of predicted PGA at a very short distance, while the standard deviation barely changes. For example, by setting $\mathrm{d}=0$ or $\mathrm{d}=10 \mathrm{~km}$ and obtaining the other parameters by regression, the standard deviation changes by less than $0.5 \%$, but the predicted PGA at a source distance of $1 \mathrm{~km}$ changes by a factor of 14 for all magnitudes.

It is acknowledged that New Zealand earthquakes may produce peak accelerations at short distances that are different to those from earthquakes in some other parts of the world. However, it was felt preferable to use overseas data to provide some near-fault constraints rather than to have very high values that were unconstrained by data and were difficult to justify in terms of motions recorded anywhere in the world.

The other criteria for selecting the overseas data were consistent with those used for the New Zealand data. Thus a moment magnitude had to be available for the event, and its centroid depth, source mechanism and the shortest distance from site to source were also required. In addition, enough had to be known about each site for its ground class to be assigned on the same basis as that of the New Zealand sites. The Pacoima dam record of 1971 was excluded because of the probable high amplification from topographic effects of the site. 


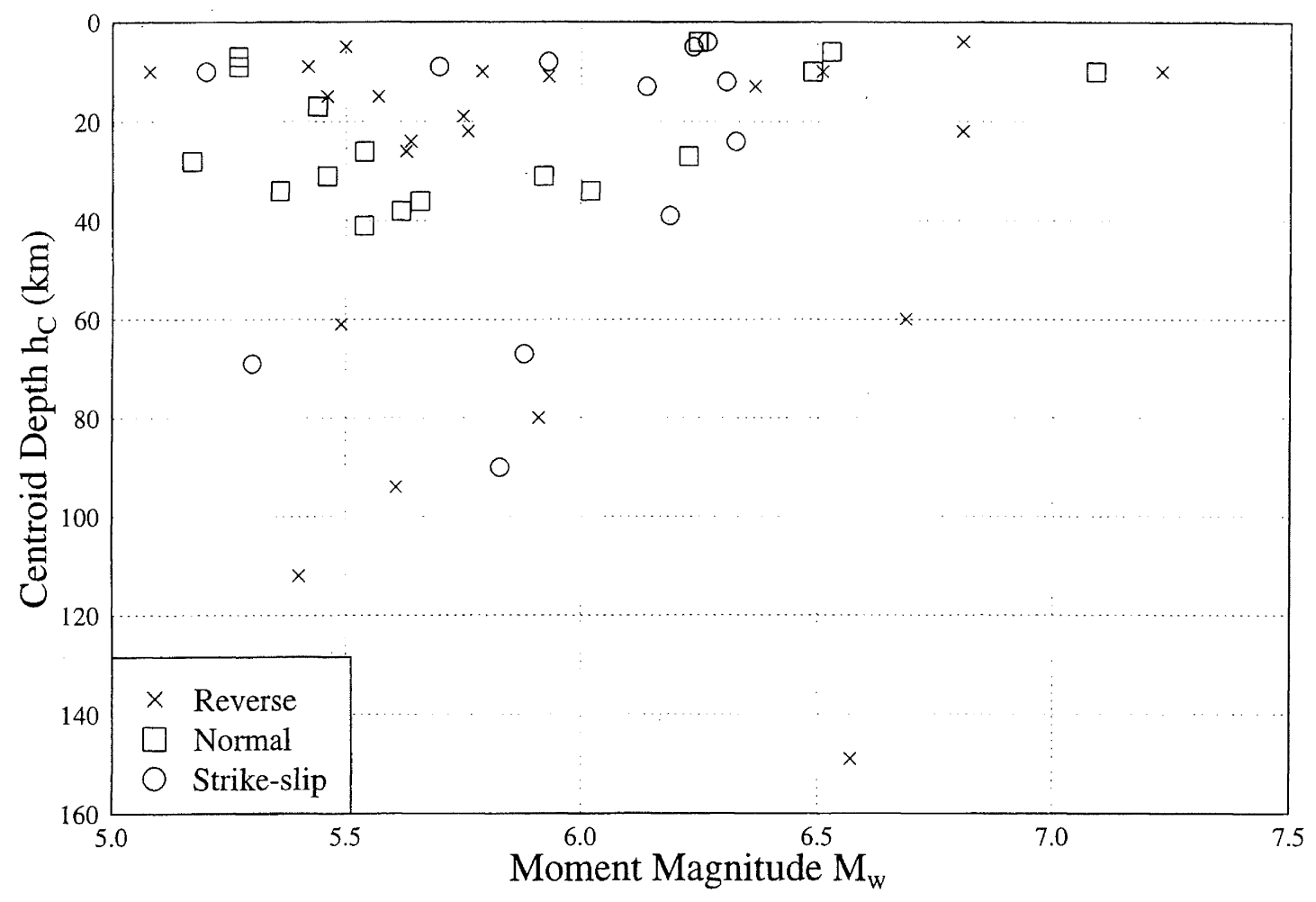

FIGURE 2 Depth $h_{C}$, focal mechanism, and $M_{W}$ for the New Zealand earthquakes considered in this study.

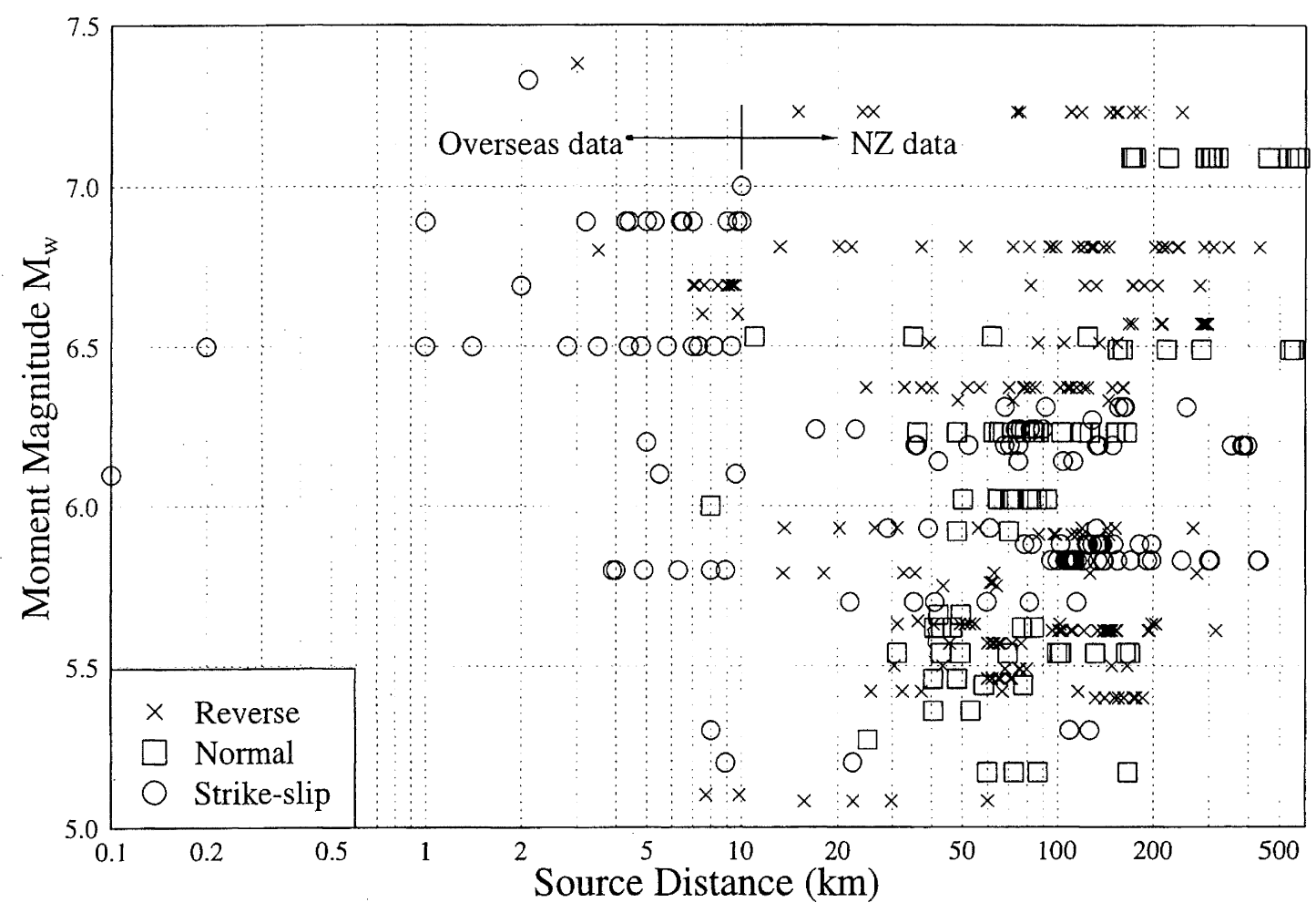

FIGURE 3 Source-to-site distance, $M_{W}$ and focal mechanism of the PGA data. The New Zealand data are those with distances $\geq 11 \mathrm{~km}$, while the overseas data have distances $\leq 10 \mathrm{~km}$. 
Table 2: Fault rupture geometry of events in New Zealand PGA data set

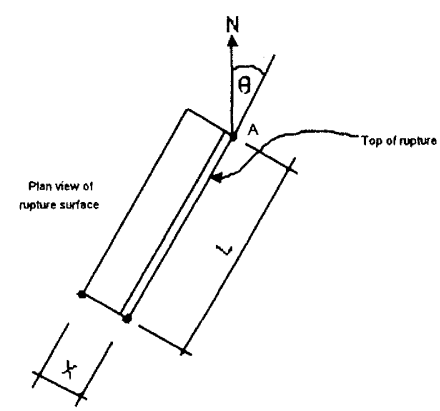

\begin{tabular}{||l|c|c|c|c|c|c|l||}
\hline \multicolumn{1}{|c|}{ Event } & $\begin{array}{c}\text { Strike } \\
\theta^{\circ}\end{array}$ & $\begin{array}{c}\text { Dip } \\
\beta^{0}\end{array}$ & $\begin{array}{c}\mathrm{L} \\
(\mathrm{km})\end{array}$ & $\begin{array}{c}\mathrm{X} \\
(\mathrm{km})\end{array}$ & $\begin{array}{c}\mathrm{h}_{\mathrm{t}} \\
(\mathrm{km})\end{array}$ & $\begin{array}{c}\mathrm{h}_{\mathrm{b}} \\
(\mathrm{km})\end{array}$ & $\begin{array}{l}\text { Point A } \\
{ }^{\circ} \mathrm{S}\end{array}$ \\
\hline $1968 / 05 / 23(\mathrm{G})$ & 27 & $45 \mathrm{NW}$ & 25 & 10 & 0 & 10 & 41.78172 .04 \\
\hline $1987 / 03 / 02$ & 55 & $\mathrm{NR}$ & 13 & $\mathrm{NR}$ & 0 & $\mathrm{NR}$ & 37.96176 .89 \\
\hline $1990 / 02 / 10$ & 55 & 90 & 21 & 0 & 2 & $\mathrm{NR}$ & 42.18172 .84 \\
\hline $1990 / 02 / 19$ & 35 & $70 \mathrm{NW}$ & 12.5 & 3 & 24 & 32 & 40.30176 .41 \\
\hline $1990 / 05 / 13$ & 40 & $40 \mathrm{NW}$ & 18 & 10 & 9 & 17 & 40.28176 .43 \\
\hline $1993 / 04 / 11$ & 45 & $15 \mathrm{NW}$ & 10 & 15 & 22 & 26 & 39.75176 .72 \\
\hline $1993 / 08 / 10(\mathrm{a})$ & 32 & $\mathrm{NR}$ & 25 & 15 & $\mathrm{NR}$ & 26 & 45.09166 .78 \\
\hline $1993 / 08 / 10(\mathrm{~b})$ & -6 & $70 \mathrm{E}$ & 12.5 & 6.5 & 30 & 50 & 38.47177 .82 \\
\hline $1994 / 06 / 18(\mathrm{P})$ & 340 & 90 & 35 & $\mathrm{NR}$ & 0 & $\mathrm{NR}$ & 42.90171 .35 \\
\hline $1995 / 11 / 24$ & -15 & $70 \mathrm{SW}$ & 10 & 3 & 1 & 9 & 42.92171 .86 \\
\hline \hline
\end{tabular}

$\begin{array}{ll}\mathrm{G} & =\text { Geodetic source model [46] } \\ \mathrm{P} & =\text { Preliminary rupture model } \\ \mathrm{L} & =\text { Length of rupture } \\ \mathrm{X} & =\text { Plan width of rupture } \\ \mathrm{h}_{\mathrm{t}} & =\text { depth to top of rupture } \\ \mathrm{h}_{\mathrm{b}} & =\text { depth to bottom of rupture } \\ \mathrm{NR} & =\text { Not required for measuring shortest distance } \\ \text { Dip angles are rounded values only }\end{array}$

In all, 66 records (horizontal components only) were selected from a total of 17 overseas crustal earthquakes (listed in Table 3) ranging in magnitude from $M_{w} 5.1$ to $M_{w}$ 7.4. The stronger horizontal component of PGA from these events ranged from $0.11 \mathrm{~g}$ to $0.98 \mathrm{~g}$. Of the 66 recordings, $18 \mathrm{had}$ values greater than the largest value $(0.58 \mathrm{~g})$ in the New Zealand data set. Source distances ranged from $0.1 \mathrm{~km}$ to $10 \mathrm{~km}$. The full data file is available (together with the New Zealand data) from the authors in computer file NZPGA.ZDM.
We did not attempt to find all overseas data that might fit the above criteria, restricting ourselves to those which were readily available. Many of the records that we used were contained in the compilation by Otsuka et al. [19], which contained near-source data from Campbell [20], although we often obtained supplementary information of required parameters from other sources, supplemented with data from the more recent Northridge and the Hyogo-ken Nanbu (Kobe) earthquakes. Given the limited distance range considered, the amount of overseas data obtained is quite large; the overseas data set is reasonably in proportion in size to the local data set for the relative distance ranges considered, and the two data sets have virtually the same magnitude range. Hence we consider the overseas dataset to be adequate for the present purpose. 
Table 3: Overseas earthquakes with near-source data used in this study

\begin{tabular}{|c|c|c|c|c|c|c|c|c|c|}
\hline No. & $\mathrm{yr}$ & $\begin{array}{r}\text { Date } \\
\text { mo }\end{array}$ & & $\begin{array}{c}\text { UT } \\
\mathrm{hr} / \mathrm{mn}\end{array}$ & Event name & $\mathrm{M}_{\mathrm{w}}$ & $\begin{array}{c}\text { Centroid } \\
\text { depth }(\mathrm{km})\end{array}$ & $\begin{array}{l}\text { Predom. } \\
\text { Source } \\
\text { Mech. }\end{array}$ & $\begin{array}{l}\text { No. of } \\
\text { PGA } \\
\text { Records }\end{array}$ \\
\hline 1 & 1940 & 05 & 19 & 0436 & Imperial Valley & 7.0 & 10 & $\mathrm{~S}$ & 1 \\
\hline 2 & 1957 & 03 & 22 & 1944 & Daly City & 5.3 & 7 & $S$ & 1 \\
\hline 3 & 1966 & 06 & 28 & 0426 & Parkfield & 6.1 & 7 & $S$ & 3 \\
\hline 4 & 1971 & 02 & & 1400 & San Fernando & 6.6 & 12 & $\mathrm{R}$ & 2 \\
\hline 5 & 1972 & 12 & & 0629 & Managua & 6.2 & 10 & $\mathrm{~S}$ & 1 \\
\hline 6 & 1974 & 11 & & 2301 & Hollister & 5.2 & 7 & S & 1 \\
\hline 7 & 1975 & 08 & & 2020 & Oroville & 6.0 & 5 & $\mathrm{~N}$ & 1 \\
\hline 8 & 1976 & 05 & & 0258 & Gazli & 6.8 & 10 & $\mathrm{R}$ & 1 \\
\hline 9 & 1978 & 08 & 13 & 1322 & Santa Barbara & 5.1 & 7 & $\mathrm{R}$ & 3 \\
\hline 10 & 1978 & 09 & 16 & 1535 & Tabas & 7.41 & 11 & $\mathrm{R}$ & 1 \\
\hline 11 & 1979 & 08 & 06 & 1705 & Coyote Lake & 5.8 & 7 & $S$ & 6 \\
\hline 12 & 1979 & 10 & 15 & 2316 & Imperial Valley & 6.5 & 10 & $S$ & 17 \\
\hline 13 & 1989 & 10 & 18 & 0004 & Loma Prieta & 6.92 & 12 & $S$ & 7 \\
\hline 14 & 1992 & 03 & 13 & 1718 & Erzincan & 6.72 & 10 & $\mathrm{~S}$ & 1 \\
\hline 15 & 1992 & 06 & 28 & 1157 & Landers & 7.36 & 7 & S & 1 \\
\hline 16 & 1994 & 01 & 17 & 1230 & Northridge & 6.72 & 12 & $\mathrm{R}$ & 12 \\
\hline 17 & 1995 & 01 & 16 & 2046 & $\begin{array}{l}\text { Hyogo-ken } \\
\text { Nanbu }\end{array}$ & 6.92 & 10 & $S$ & 7 \\
\hline
\end{tabular}

\subsection{DEVELOPMENT OF THE ATTENUATION MODEL}

The initial functional form for the attenuation model was selected as

$$
\log _{10}(\mathrm{PGA})=\mathrm{A} \mathrm{M}_{\mathrm{W}}+\mathrm{B} \log _{10}(\mathrm{r})+\mathrm{Cr}+\mathrm{D}
$$

PGA is the peak ground acceleration of the stronger of the two orthogonal horizontal components, in units of $g$. The moment magnitude is denoted by $\mathrm{M}_{\mathrm{w}}$ and $\mathrm{r}$ is defined as the shortest distance in kilometres from the fault rupture surface to the recording station. Least-squares regression was performed on the New Zealand data set. Then residuals of the regression model, i.e. the difference between the logarithm of the recorded PGA and that of the PGA predicted by Equation (1), were calculated for each ground class, focal mechanism and three depth classes with depths $h_{C}$ of $0-20 \mathrm{~km}, 20.1-50 \mathrm{~km}$ and $50.1-150 \mathrm{~km}$. At a late stage in the model development, the tectonic type (crustal, interface or slab) of the earthquakes was also considered in the residual analysis.

The ground classes (discussed earlier) are AT, AL, AR, AV, B and $C$ as well as soft soil and deep soil sub-classes in ground classes B and C. "Soft soil" is defined such that the average shear-wave velocity is $\leq 200 \mathrm{~m} / \mathrm{s}$ in the soil to the shallower of effective bedrock or $30 \mathrm{~m}$ depth. The mean residual values for ground classes $\mathrm{AL}, \mathrm{B}$, and $\mathrm{C}$ and sub-classes of soft soil and deep soil sites were not different at a significance level of $5 \%$ in statistical terms, ie, they were "similar" (this term will be used in the following text for simplicity instead of the formal statistical term). The mean residual values for ground classes AT, AR and $\mathrm{AV}$ were similar, but the mean residual values for the combined group of ground classes AT, AR and AV (referred to hereafter as rock sites) and for the combined group of ground classes AL, B and $\mathrm{C}$ (referred to hereafter as soil sites) were "different", ie, different at a significance level of $5 \%$.

For crustal events, the mean values of the residuals were statistically similar for normal faults and strike-slip faults, but the mean value of residuals for the reverse fault events was statistically different from that for the combined group of events with normal and strike-slip focal mechanisms.

Residuals were also evaluated for earthquakes with different centroid depths. The data set was divided into three depth classes, $0-20 \mathrm{~km}, 20.1-50 \mathrm{~km}$ and $50.1-150 \mathrm{~km}$, and it was found that the mean values of residuals were statistically different for each of the three depth classes. The plot of residuals against depth also shows a trend of depth dependence, with the strength of shaking increasing with depth when other parameters are held fixed.

For slab events, the effect of focal mechanism was found to be statistically insignificant for the mean residuals. The mean residuals for records from slab events were found to be similar to those for crustal records when the mechanism term was included for the crustal events.

Interface events, although all having a substantial reverse component, were found to produce significantly lower PGAs than crustal or slab events. For this reason, it was important to separate 
the crustal reverse events (higher PGAs) from the interface events (lower PGAs), otherwise the effect of source mechanism is statistically insignificant.

For the case of an earthquake with a ground surface rupture, the attenuation model in Equation (1) will give an artificially large PGA for a site close to a fault, ie when $r$ becomes small. This mathematical effect was dealt with using the approach of Joyner and Boore [21] and Boore et al [22, 23], by adding a constant, $d$, to $r$ in the logarithm term.

We have placed some constraints on the coefficients in Equation (1). We have assumed that PGA is an increasing function of magnitude, so A must be positive. Also, we have assumed that PGA is a decreasing function of distance, so $\mathrm{B}$ and $\mathrm{C}$ must be negative. This assumption is true when considering the full range of distance from source to the far field, although it is sometimes violated over relatively short distance ranges by effects such as reflections off the Moho. Coefficient $C$ in Equation (1) is usually very small, and sometimes becomes positive in regression analyses because of the data distribution and the interdependence of estimates of B and C. So in our analyses, when coefficient C was positive, $\mathrm{C}$ was set to zero. This occurred in all of our final models, so that the Cr term does not appear in them.

Finally, the error in the estimates of attenuation parameters must also be considered. Statistical tests were carried out, and any parameter that was not larger than zero at a significance level of $5 \%$ was excluded.

To account for the effects suggested by the results of the above analyses, the regression model was developed from eq. (1) into

$$
\begin{gathered}
\log _{10}(\mathrm{PGA})=\mathrm{A}_{1} \mathrm{M}_{\mathrm{W}}+\mathrm{A}_{2} \log _{10} \sqrt{\mathrm{r}^{2}+\mathrm{d}^{2}}+\mathrm{A}_{3} \mathrm{~h}_{\mathrm{C}}+\mathrm{A}_{4}+ \\
\mathrm{A}_{5} \delta_{\mathrm{R}}+\mathrm{A}_{6} \delta_{\mathrm{A}}+\mathrm{A}_{7} \delta_{\mathrm{I}}
\end{gathered}
$$

where $d$ is a constant to restrain the near-source PGA prediction and $h_{C}$ is the centroid depth of the rupture surface. The dummy variables are defined as

$$
\begin{aligned}
& \delta_{\mathrm{R}}= \begin{cases}1 & \text { for crustal reverse faults } \\
0 & \text { for all other events }\end{cases} \\
& \delta_{\mathrm{A}}= \begin{cases}1 & \text { for all rock sites (i.e. AT, AR and AV) } \\
0 & \text { for all soil sites (i.e. AL, B and C) }\end{cases} \\
& \delta_{\mathrm{I}}= \begin{cases}1 & \text { for interface events } \\
0 & \text { for all other events }\end{cases}
\end{aligned}
$$

Equation (2) is not linear in the parameters because of parameter d. If parameter $d$ is taken as a constant for each iteration, Equation (2) is still a linear model and variances calculated for all parameters are conditional variances, ie, under a condition that parameter $d$ is constant, but the variance for parameter $d$ cannot be estimated.
We believe that this is the first single model to be developed which combines a mechanism term, a centroid depth term, and a tectonic type term, with all parameters shown to be statistically significant.

The following models were derived using only the data from the "Main Seismic Region," i.e. excluding data with travel paths in the Central Volcanic Region (CVR), i.e. all data from events 19 and 42, and all but one record from event 47 . Our first model, Model 1, was derived by simultaneous consideration of the total remaining data set and solving for values of all of the parameters in Equation (2).

The same functional form, but with the $\delta_{\mathrm{A}}$ coefficient $\mathrm{A}_{6}$ taken as zero, was also used for Model 2 which was derived considering soil site data only. The PGAs given by this model are similar to those from Model 1 for soil sites. Parameter $A_{6}$ was taken as zero for this model. An attempt to create a similar model derived from the rock site data only, was unsuccessful, because there are too few rock site data.

A further model, Model 3, was developed to deal with applications where the site conditions are unknown or unspecified. For this model, parameter $\mathrm{A}_{6}$ was set to zero, as for Model 2, but all the data were used. The PGAs predicted by this model reflect the dominance of the number of soil site records against rock site records in the dataset, in that they are similar to those from Models 1 and 2 for soil sites.

Model 4 was developed to deal with applications where the site conditions are known, but the focal mechanism and tectonic type are unknown or unspecified. In this case, the coefficients $A_{5}$ and $\mathrm{A}_{7}$ of the $\delta_{\mathrm{R}}$ and $\delta_{\mathrm{I}}$ terms were set to zero.

Finally, Model 5 was developed to deal with situations where only the magnitude, depth and distance are known or specified. In this case, the coefficients $A_{5}, A_{6}$ and $A_{7}$ of the $\delta_{R}, \delta_{A}$ and $\delta_{1}$ terms were set to zero.

The parameters of the above attenuation models are given in Table 4, along with the number of PGA data, N, used for each model. Their corresponding conditional standard errors are given in Table 5.

Table 6 summarises the results of statistical testing that shows that Model 1 gives good fits of various subclasses at data. For all subclasses identified in Table 6, the hypothesis that the mean residual is zero cannot be rejected at significance levels of $5 \%$ or sometimes even less. Also, the RMS and mean residuals are statistically similar in the sets of comparisons indicated. The subclasses considered include: tectonic type; mechanism and tectonic class; ground condition; New Zealand vs. overseas data; and basement data from buildings of greater than three storeys $v s$. free-field data and basement data from buildings of $\leq$ three storeys.

The fits of various subclasses of data by Models 1 to 5 are summarised in Table 7, with the results indicating the need for the various parameters included in Model 1.

For soil data, Models 1 and 2 are equally good, and give virtually identical PGA values.

The residual analyses for Model 3 for the rock and soil subclasses show the need for the ground class term in Model 1. Without it, 
the mean residuals for both subclasses are significantly different from zero. Without a tectonic class or mechanism term, the residual analyses for Model 4 show that crustal normal or strikeslip and slab event data are predicted satisfactorily, but crustal reverse and interface event data are not. The overall RMS residual for Model 4 is only slightly increased from that for Model 1 , but the non-unity mean residual factors and large RMS residuals at Model 4 for the crustal reverse and interface event data show the need for the mechanism and tectonic type terms, as supported by the formal hypothesis testing.

\subsection{DISCUSSION OF THE ATTENUATION MODEL}

As discussed above, we have obtained expressions which model attenuation of PGA in most parts of New Zealand, in terms of magnitude, distance, depth, focal mechanism, tectonic type and ground class. Various features of the models are discussed below.

\subsection{Functional Form of the Model}

The functional form that we have used results in models which fit the data well, as illustrated for Model 1 by the plots of residuals against magnitude, source-to-site distance, and depth, as shown in Figures 4(a) - (c) respectively. However, we note that the functional forms of the models that we have selected do not allow for the possibility of "saturation" of mean PGA values at large magnitudes, as could be achieved by a magnitude-dependent added distance term, for example as in the studies by Campbell [20], Fukushima and Tanaka [24], Crouse [25] and Idriss [26,27]. We considered a magnitude-dependence of the $\log _{10} \sqrt{ }\left(\mathrm{r}^{2}+\mathrm{d}^{2}\right)$ term, i.e. $(\alpha+\beta M) \log _{10} \sqrt{ }\left(\mathrm{r}^{2}+\mathrm{d}^{2}\right)$, as used by Abrahamson and Silva [28]. The variation of the magnitude dependence with distance was found to be minor. Also, the estimates at $\alpha$ and $\beta$ were found to be highly coupled with each other, and also with the coefficients of the magnitude term and constant term. The estimates of the coefficients of the magnitude and constant terms were not significantly different from zero for this form of model. We rejected this type of model because of these problems.

We have assumed that the standard deviation of the scatter about the mean values is independent of magnitude and distance, while recent studies, e.g. Idriss [26,27], Abrahamson and Silva [28], and Youngs et al [29], have indicated that the standard deviations decrease with increasing magnitude. Alternatively, other studies, Donovan and Bornstein [30] and Campbell and Bozorgnia [31], have incorporated an amplitude-dependent standard deviation, with smaller values at larger amplitudes.

The lack of magnitude saturation in the mean values and constant standard deviations at all magnitudes and amplitudes may lead to very high near-source estimates of PGA which cannot (at present) be confirmed by measured data. Magnitudes beyond $\mathrm{M}_{\mathrm{W}} 7.2$ and distances less than $11 \mathrm{~km}$ lie outside the current range of the New Zealand data.

The uncertainties in the estimates of the individual parameters for the various models are discussed below. However, another important consideration in regression analysis is the degree of correlation in the estimates of the various parameters. A high degree of correlation indicates that the data are inadequate to estimate some of the parameters in the model.

The coefficients of correlation between the uncertainties in estimates of various model parameters $A_{i}$ can be determined by the normalised covariance matrix of the regression model. If the uncertainties in the estimates of any two parameters of the model are highly correlated or anti-correlated, the corresponding term of the normalised covariance matrix, $\operatorname{COV}\left(\mathrm{A}_{\mathrm{i}}, \mathrm{A}_{\mathrm{j}}\right) / \sigma_{\mathrm{A}_{\mathrm{i}}} \sigma_{\mathrm{A}_{\mathrm{j}}}$, will be close to +1 or -1 , and if not correlated, the corresponding term of the normalised covariance matrix will be close to zero. It is found that for all five models presented in this paper, only the uncertainties associated with parameters $A_{1}$ and $A_{4}$, i.e. the coefficients of the magnitude term and the constant, are highly anti-correlated (the normalised covariance coefficient is about $-0.9)$. The absolute values of all the other normalised covariance coefficients are less than 0.5 , indicating weak correlation between the uncertainties associated with these parameters.

These results indicate that in the main the data are adequate for estimating the parameters of the model. The high degree of anticorrelation between the estimate of the coefficient of the magnitude term and of the constant term suggests that a more reliable model could be obtained with an expanded dataset covering a greater magnitude range. This improvement must await the recording of more large magnitude earthquakes, particularly to increase the upper limit of the $M_{W}$ range, and the development of techniques for obtaining $M_{w}$ for lower magnitude events.

\subsection{Robustness}

As seen in Table 4, the standard error in the estimate of $\log _{10}$ PGA ranges from 0.230 to 0.246 for the various models. These values suggest reasonable precision of the estimate of mean PGA, and lie within the range of values $(0.13-0.30)$ obtained by other researchers over the last 15 years. The standard error tends to decrease with increasing number of parameters fitted. Model 1 , which fits all of the parameters has the smallest standard error, while Model 5 which fits the least of the parameters has the largest standard error. The improvement in the standard error (ie measure of fit) as additional parameters are included, is modest for the dataset as a whole, but as shown in the following sections is important and statistically significant for various subclasses of the data.

The conditional standard errors of the parameters $A_{1}$ to $A_{7}$ provide insight into how well the model is determined. These values are given in Table 5. Here it is seen that the conditional standard errors, like those on $\log _{10}$ PGA discussed above, are mostly smaller for Model 1 than for the other models. In addition it is noted that the conditional standard errors are relatively small compared to the values of their respective parameters (Table 4). This is an important indicator of robustness of the models.

\subsection{Effect of Depth}

Studies in other parts of the world have shown that depth influences the strength of shaking other than simply as a function of source-to-site distances [25, 33]. Earlier studies [2,4,5] showed that New Zealand earthquakes with depths greater than about 50 $\mathrm{km}$ produced stronger accelerations than shallower events of the same magnitude and source distance, but there were insufficient data to robustly model this effect. However in the present study, with more data, a single model has been found with depth accounted for as a simple linear function of centroid depth over and above the source distance term, as used by Molas and Yamazaki for Japan [33] and by Crouse for the Cascadia subduction zone [25]. 


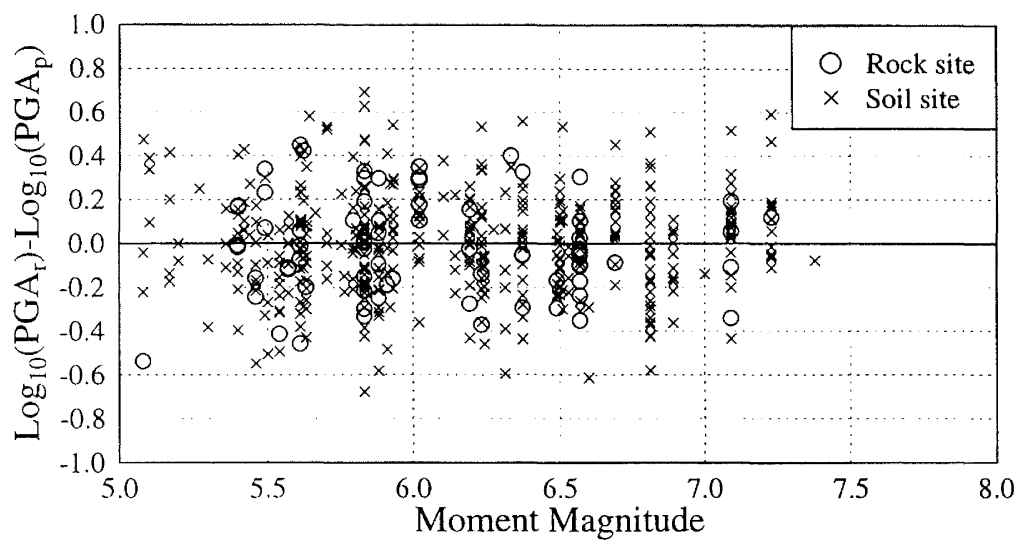

(a)

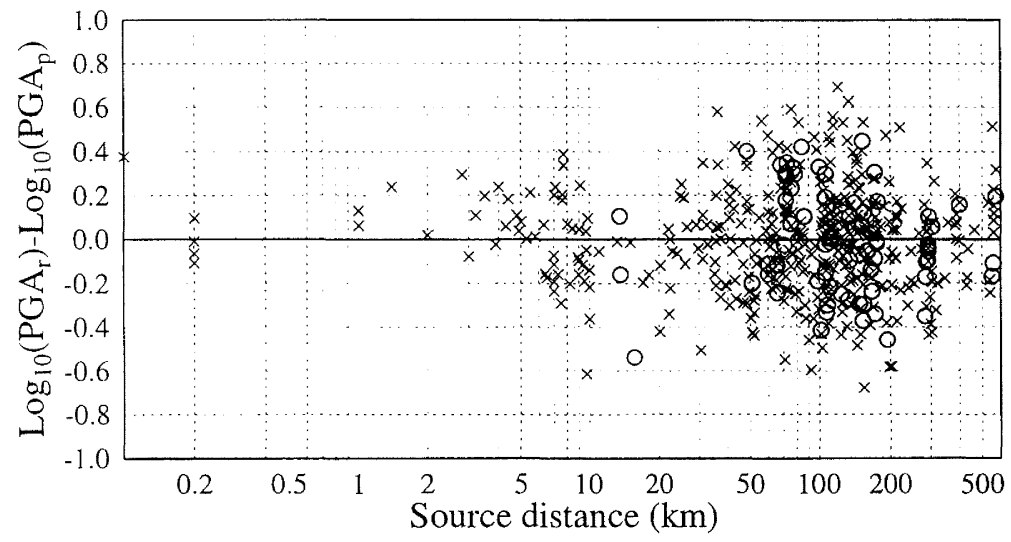

(b)

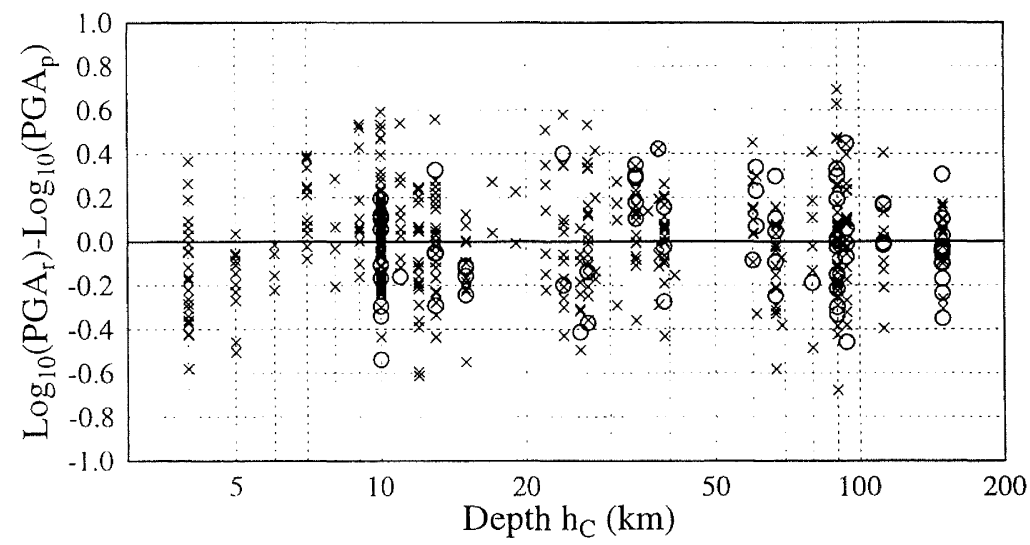

(c)

FIGURE 4 Residuals of the PGA data for Model 1 plotted against (a) magnitude $M_{W,}$ (b) shortest source-to-site distance $r$, and $(c)$ depth $h_{C} . P G A_{r}=$ recorded $P G A$ and $P G A_{p}=$ predicted $P G A$. Rock and soil site data are indicated. Note the uniformity of the residuals. 
Table 4: Attenuation model parameters

\begin{tabular}{|l|l|l|l|l|l||}
\hline & Model 1 & Model 2 & Model 3 & Model 4 & Model 5 \\
\hline & All data & Soil data & $\begin{array}{l}\text { Site conditions } \\
\text { unknown }\end{array}$ & $\begin{array}{l}\text { Earthquake } \\
\text { types and focal } \\
\text { mechanisms } \\
\text { unknown }\end{array}$ & $\begin{array}{l}\text { Earthquake types, } \\
\text { focal mechanisms and } \\
\text { site conditions } \\
\text { unknown }\end{array}$ \\
\hline $\mathrm{A}_{1}\left(\mathrm{M}_{\mathrm{w}}\right)$ & 0.298 & 0.289 & 0.297 & 0.331 & 0.331 \\
\hline $\mathrm{A}_{2}\left(\log _{10} \mathrm{r}\right)$ & -1.56 & -1.53 & -1.58 & -1.58 & -1.59 \\
\hline $\mathrm{A}_{3}\left(\mathrm{~h}_{\mathrm{c}}\right)$ & 0.00619 & 0.00611 & 0.00576 & 0.00604 & 0.00566 \\
\hline $\mathrm{A}_{4}($ Constant) & -0.365 & -0.357 & -0.333 & -0.509 & -0.490 \\
\hline $\mathrm{A}_{5}(\mathrm{Reverse})$ & 0.107 & 0.108 & 0.101 & - & - \\
\hline $\mathrm{A}_{6}(\mathrm{G} . \mathrm{C})$. & -0.186 & - & - & -0.190 & - \\
\hline $\mathrm{A}_{7}(\mathrm{Type})$ & -0.124 & -0.111 & -0.141 & - & - \\
\hline $\mathrm{d}$ & 19 & 19 & 20 & 19 & 20 \\
\hline$\sigma_{\text {log } 10}$ PGA & 0.230 & 0.231 & 0.240 & 0.237 & 0.246 \\
\hline $\mathrm{N}^{* *}$ & 527 & 443 & 527 & 527 & 527 \\
\hline Neq* & 49 & 49 & 49 & 49 & 49 \\
\hline \hline
\end{tabular}

** $\quad \mathrm{N}=$ Number of PGA data

* $\quad$ Neq $=$ Number of New Zealand events

Table 5: Conditional standard errors of model parameters

\begin{tabular}{|l|l|l|l|l|l||}
\hline & Model 1 & Model 2 & Model 3 & Model 4 & Model 5 \\
\hline $\mathrm{A}_{1}$ & 0.0210 & 0.0230 & 0.0218 & 0.0206 & 0.0214 \\
\hline $\mathrm{A}_{2}$ & 0.0307 & 0.0333 & 0.0324 & 0.0314 & 0.0331 \\
\hline $\mathrm{A}_{3}$ & 0.00033 & 0.00038 & 0.00033 & 0.00031 & 0.00031 \\
\hline $\mathrm{A}_{4}$ & 0.130 & 0.144 & 0.136 & 0.129 & 0.135 \\
\hline $\mathrm{A}_{5}$ & 0.0275 & 0.0295 & 0.0286 & & \\
\hline $\mathrm{A}_{6}$ & 0.0280 & & & 0.0288 & \\
\hline $\mathrm{A}_{7}$ & 0.0397 & 0.0435 & 0.0413 & & \\
\hline
\end{tabular}

The coefficient for the depth term in Model 1 is 0.00619 . Excluding interface events, this predicts mean PGAs of events with $h_{C}=35 \mathrm{~km}$ that are 1.43 times stronger than those with $\mathrm{h}_{C}=$ $10 \mathrm{~km}$, while if $\mathrm{h}_{\mathrm{C}}=150 \mathrm{~km}$ the PGAs are 7.36 times stronger than when $h_{C}=10 \mathrm{~km}$, holding all other parameters equal. This depth dependency is illustrated in Figure 5. The predicted increase of strength of shaking with depth is not as great in the Japanese [33] and Cascadia [25] models noted above, the predicted PGAs for a depth of $150 \mathrm{~km}$ being respectively 2.73 and 3.61 times those for a depth of $10 \mathrm{~km}$. In both these models interface and slab events are combined into a single subclass.
The fit of Model 1 to the data may be examined visually for two events of different depth in Figure 6, for the 1993 Ormond earthquake (event 45), and in Figure 7, for the 1973 Central North Island earthquake (event 7). These earthquakes had centroid depths of 39 and $149 \mathrm{~km}$ respectively, and both were slab events, but with strike-slip and reverse mechanisms respectively. The latter event illustrates the fit of the model to the data at the extreme of the depth range. These examples confirm the impression given by the residuals plotted against depth for the whole data set in Figure 4(c), that the model fits the data reasonably well over the whole depth range of the data set, i.e. down to a depth of $150 \mathrm{~km}$. This probably exceeds the greatest depth of design interest. 


\subsection{Effect of Tectonic Type}

Models 1-3 show that the seven earthquakes which were located on the interface between the tectonic plates, ie the Interface events (I) in Table 1, produced PGAs which were smaller on average than those of crustal or slab events of the same magnitude, depth and distance. The coefficient for the tectonic type term $A_{7}$ in Model 1 is -0.124 , which predicts that the mean PGAs of Interface events are 25 percent less than non-interface events of the same magnitude, depth and distance. It should be noted that the coefficient $A_{7}$ of the tectonic type term is less well-constrained than coefficients $A_{5}$ and $A_{6}$ of the mechanism and ground class terms, i.e. the conditional standard errors (Table 5) are such that its coefficient of variation ( 0.32 for Model 1$)$ is larger than those of $A_{5}$ and $A_{6}$. This difference may reflect the small number (only 7) of interface events in the data set. Inclusion of the interface term is important. Like all the retained coefficients, $A_{7}$ has been shown to be statistically different from zero. Without this term, the mean residual for interface events is significantly less than zero. Also, its absence makes the reverse mechanism for crustal earthquakes statistically insignificant.

\subsection{Effect of Focal Mechanism}

Previous studies of both strong ground motion records, e.g. Campbell [20], Campbell and Bozorgina [31], and Idriss [27], and intensities (Dowrick [34]) have found that earthquakes with predominantly reverse focal mechanisms produce stronger shaking for the same magnitude and distance than do events with predominantly normal or strike-slip mechanisms. Abrahamson and Silva [28] differentiate between strike-slip or normal faults, oblique faults and reverse faults. They also differentiate between hanging wall and foot wall locations for dipping faults, at distances up to $25 \mathrm{~km}$ from the rupture plane. The present study finds that the coefficient for the focal mechanism term in Model 1 is 0.107 . This corresponds to mean PGAs for reverse faulting crustal events which are on average 28 percent greater than for other crustal events at all magnitudes and distances, as illustrated in Figure 5. Idriss [27] found an increase of $22 \%$ for reverse faults. The result is also similar to the average difference of about 31 percent previously found for New Zealand by Dowrick [34], by an approximate conversion of intensities to PGAs. Campbell and Bozorgnia's model [31] gives PGAs from reverse faulting events that average about 40 percent larger than those of strikeslip events very close to the source, but the difference decreases with increasing distance and magnitude. This effect was also found for intensities by Dowrick [34]. Our model simply gives the difference which is appropriate on average over the whole data set. This model is supported by an examination of the residuals of the crustal reverse event data, which shows no strong trends as a function of magnitude or distance.

The data from a shallow normal-faulting event, the $M_{w} 6.61987$ Edgecumbe earthquake, are compared with Model 1 in Figure 8, while the data and Model 1 for a shallow reverse-faulting event, the $M_{w} 7.21968$ Inangahua earthquake, are plotted on Figure 9(a).

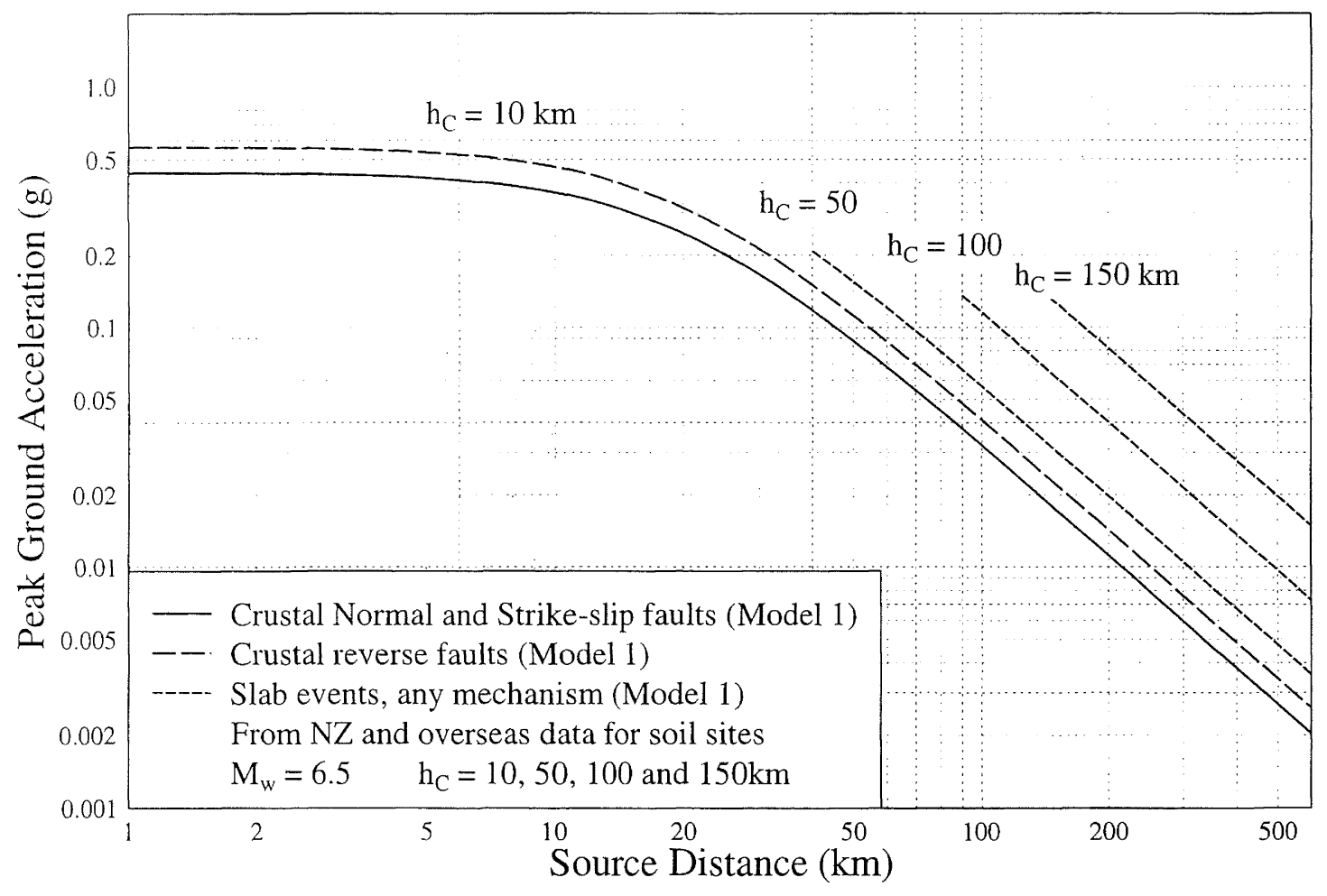

FIGURE 5 Effect of depth and mechanism. PGA plotted against source distance $r$ as predicted by Model 1, for non-interface events of depth $h_{C}=10,50,100$ and $150 \mathrm{~km}$. 
Table 6: Fit of Model 1 to subclasses of New Zealand data

\begin{tabular}{|c|c|c|c|}
\hline & Mean Residual Factor & RMS Residual & No. of Data \\
\hline \multicolumn{4}{|c|}{ Tectonic type } \\
\hline Crustal & 1.03 & 0.247 & 166 \\
\hline Interface & 1.00 & 0.248 & 42 \\
\hline Slab & 0.987 & 0.223 & 253 \\
\hline \multicolumn{4}{|c|}{ Mechanism and tectonic type } \\
\hline Crustal N & 0.975 & 0.201 & 39 \\
\hline Crustal R & 1.03 & 0.263 & 98 \\
\hline Crustal S & 1.12 & 0.201 & 29 \\
\hline Slab N & 0.943 & 0.231 & 71 \\
\hline Slab R & 0.956 & 0.211 & 84 \\
\hline Slab S & 1.05 & 0.230 & 98 \\
\hline \multicolumn{4}{|c|}{ Ground condition } \\
\hline Ground class A & 1.02 & 0.241 & 114 \\
\hline Ground class B & 0.997 & 0.231 & 110 \\
\hline Ground class $\mathrm{C}$ & 1.00 & 0.233 & 237 \\
\hline Ground class AL & 0.985 & 0.262 & 41 \\
\hline Ground class Rock & 1.04 & 0.230 & 73 \\
\hline \multicolumn{4}{|c|}{ New Zealand $v s$. overseas data } \\
\hline $\mathrm{NZ}$ data & 1.00 & 0.234 & 461 \\
\hline Overseas data & 0.97 & 0.193 & 66 \\
\hline \multicolumn{4}{|c|}{ Building height } \\
\hline Basement data ( $>3$ storey) & 1.03 & 0.177 & 33 \\
\hline $\begin{array}{l}\text { Free field and Basement data } \\
\text { ( } \leq 3 \text { storey) }\end{array}$ & 1.00 & 0.238 & 428 \\
\hline
\end{tabular}

Residual $=\log _{10} \mathrm{PGA}_{\text {recorded }}-\log _{10} \mathrm{PGA}$ predicted

Mean residual factor $=10^{- \text {mean residual }}=$ geometric mean of predicted $/$ recorded PGA

The RMS and mean residuals for all subclasses are statistically similar and mean residuals for all subclasses are not different from zero at a significance level of $5 \%$.

\subsection{Effect of Ground Class}

Various overseas studies have produced attenuation models that differentiate between PGAs for different ground classes, eg References $20,22-24,26,28,31$, but this has not previously been possible for New Zealand because of the scarcity of data. However with the current data set, regression analyses have produced statistically supported insights into the influence of ground class on PGA within the attenuation functions. As noted in Section 4.0 above, the New Zealand recording sites have been classified into three main ground classes, A, B and C, corresponding to those of the New Zealand loadings code NZS4203:1992, and each of these was sub-divided into a number of sub-classes. Residual analyses were carried out on different sub-sets of the data examining the significance of various of the ground sub-classes and combinations thereof. Statistical tests showed that only two types of site were significantly different from the others but similar to each other, namely (i) those sites with surface rock, and (ii) sites with a soil deposit $\leq 3 \mathrm{~m}$ thick overlying bedrock. These two types of site (actually three subclasses AR, AV, AT, see Section 4.0) were lumped together to comprise our "rock" sites. We note that if the soil layer thickness had been increased to $10 \mathrm{~m}$, there would have been little change to the "rock" data set from the addition of the few records from those sites in the soil depth range 3-10 metres.

Two ways of modelling the soil effects through the regression analyses have been explored, (i) a regression analysis of the whole data set, resulting in a single attenuation expression, and (ii) a separate regression analysis of the rock and non-rock (soil) data, resulting in separate attenuation expressions for these two ground classes.

Approach (i) produces a model, Model 1, which is statistically slightly more robust than approach (ii), as discussed in Section 7.2. Its coefficient for the Ground Class term is -0.186 . This 
Table 7: Evaluation of models for subclasses of data

\begin{tabular}{|c|c|c|c|c|c|}
\hline & $\begin{array}{c}\text { Model l } \\
\text { (Preferred, includes site } \\
\text { condition, earthquake type } \\
\text { \& mechanism term) }\end{array}$ & $\begin{array}{l}\text { Model } 2 \\
\text { (Soil data } \\
\text { only) }\end{array}$ & $\begin{array}{l}\text { Model } 3 \\
\text { (No site } \\
\text { term) }\end{array}$ & $\begin{array}{c}\text { Model } 4 \\
\text { (No carthquake } \\
\text { type or mechanism } \\
\text { term) }\end{array}$ & $\begin{array}{c}\text { Model } 5 \\
\text { (No site condition, } \\
\text { carthquake type or } \\
\text { mechanism term) }\end{array}$ \\
\hline $\begin{array}{c}\text { Rock sites }\left(N^{\prime}=73\right) \\
\text { MRF }^{2} \\
\text { RMS residual } \\
\text { Model accepted? }\end{array}$ & $\begin{array}{c}1.04 \\
0.230 \\
\text { Yes }\end{array}$ & $N R^{4}$ & $\begin{array}{l}1.46 \\
0.230 \\
\text { No }\end{array}$ & & $\begin{array}{c}1.48 \\
0.293 \\
\text { No }\end{array}$ \\
\hline $\begin{array}{c}\text { Soil sitcs }(N=388) \\
\text { MRF } \\
\text { RMS residual } \\
\text { Model accepted? }\end{array}$ & $\begin{array}{l}1.00 \\
0.235 \\
\text { Yes }\end{array}$ & $\begin{array}{c}1.00 \\
0.235 \\
\text { Yes }\end{array}$ & $\begin{array}{l}0.94 \\
0.237 \\
\text { No }\end{array}$ & & $\begin{array}{c}0.93 \\
0.242 \\
\text { No }\end{array}$ \\
\hline $\begin{array}{c}\text { Crustal }(N=166) \\
\text { MRF } \\
\text { RMS residual } \\
\text { Model accepted? }\end{array}$ & $\begin{array}{l}1.03 \\
0.247 \\
\text { Yes }\end{array}$ & & & & \\
\hline $\begin{array}{c}\text { Crustal } R(N=98) \\
\text { MRF } \\
\text { RMS residual } \\
\text { Model accepted? }\end{array}$ & $\begin{array}{c}1.03 \\
0.263 \\
\text { Yes }\end{array}$ & & & $\begin{array}{c}0.86 \\
0.273 \\
\text { No }\end{array}$ & $\begin{array}{c}0.87 \\
0.281 \\
\text { No }\end{array}$ \\
\hline $\begin{array}{c}\text { Crustal N/SS ( } N=68) \\
\text { MRF } \\
\text { RMS residual } \\
\text { Model accepted? }\end{array}$ & $\begin{array}{c}1.036 \\
0.224 \\
\text { Yes }\end{array}$ & & & $\begin{array}{c}1.10 \\
0.229 \\
\text { Yes }\end{array}$ & $\begin{array}{c}1.10 \\
0.243 \\
\text { Yes }\end{array}$ \\
\hline $\begin{array}{c}\text { Slab data }(\mathrm{N}=253) \\
\text { MRF } \\
\text { RMS residual } \\
\text { Model accepted? }\end{array}$ & $\begin{array}{c}0.987 \\
0.223 \\
\text { Yes }\end{array}$ & & & $\begin{array}{c}0.99 \\
0.222 \\
\text { Yes }\end{array}$ & $\begin{array}{c}0.99 \\
0.232 \\
\text { Yes }\end{array}$ \\
\hline $\begin{array}{c}\text { Slab N/SS }(N=169) \\
\text { MRF } \\
\text { RMS residual } \\
\text { Model accepted? }\end{array}$ & $\begin{array}{l}1.00 \\
0.230 \\
\text { Yes }\end{array}$ & & & & \\
\hline $\begin{array}{c}\text { Slab reverse }(\mathrm{N}=84) \\
\text { MRF } \\
\text { RMS residual } \\
\text { Model accepted? }\end{array}$ & $\begin{array}{c}0.956 \\
0.211 \\
\text { Yes }\end{array}$ & & & & \\
\hline $\begin{array}{c}\text { Interface }(\mathrm{N}=42) \\
\text { MRF } \\
\text { RMS residual } \\
\text { Model accepted? }\end{array}$ & $\begin{array}{c}1.00 \\
0.248 \\
\text { Yes }\end{array}$ & & & $\begin{array}{l}1.35 \\
0.274 \\
\text { No }\end{array}$ & $\begin{array}{c}1.40 \\
0.301 \\
\text { No }\end{array}$ \\
\hline $\begin{array}{c}\text { NZ data }(N=461) \\
\text { MRF } \\
\text { RMS residual }\end{array}$ & $\begin{array}{c}1.00 \\
0.234\end{array}$ & $\begin{array}{c}(\mathrm{N}=388) \\
1.00 \\
0.235\end{array}$ & $\begin{array}{c}1.00 \\
0.245\end{array}$ & $\begin{array}{c}1.00 \\
0.239\end{array}$ & $\begin{array}{c}1.00 \\
0.251\end{array}$ \\
\hline $\begin{array}{l}\text { All data }(\mathrm{N}=527) \\
\text { RMS residual }\end{array}$ & 0.230 & $\begin{array}{c}(\mathrm{N}=443) \\
0.231\end{array}$ & 0.240 & 0.237 & 0.246 \\
\hline
\end{tabular}

Residual analyses for subclasses are for New Zealand data only, excluding the 66 overseas records used in the regression analyses for deriving the models.

$\mathrm{N}=$ number of records in subclass

$\mathrm{MRF}=$ Mean residual factor $=10^{- \text {Mean residual of } \log 10 \mathrm{PGA} \text { for subclass }}$

Model accepted if mean residual of $\log _{10}\left(\mathrm{PGA}_{\text {data }}\right)$ minus $\log _{10}\left(\mathrm{PGA}_{\text {model }}\right)$ is zero at $5 \%$ significance level

$4 \quad$ NR $=$ Evaluation not relevant for subclass

corresponds to Model 1 predicting mean PGAs for non-rock sites which are $53 \%$ greater than for rock sites averaged over the data for all magnitudes and distances. Comparisons of the data and Model 1 for soil and rock are illustrated for the three previously discussed events in Figures 6, 7 and 9(a).

Approach (ii) produces Model 2 for soil sites. Model 2 is based on a sufficiently large data set (443 observations) to result in a reasonably robust model, almost as good as that of approach (i), i.e. Model 1 , as seen by comparing their conditional standard errors of the model parameters in Table 5.

There is considerable evidence (e.g. Refs 35-37) that weak soils will not transmit strong motion in a linear fashion. In a comparison of PGAs on rock and on soft soils, the data and theory of Idriss [36] showed this non-linearity, and combined with data from modelling studies suggested that, for the mean of the data,
PGAs on soft soil would be less than on rock at accelerations above about $0.4 \mathrm{~g}$ for magnitude 7 earthquakes and at lower accelerations for smaller magnitude events [38], with the crossover at about $0.25 \mathrm{~g}$ at magnitude $51 / 2$. Abrahamson and Silva [28] modelled the effect of soil nonlinearity explicitly. A study [37] of damage to single-storey houses in Napier in 1931 implied that short period vibration (and therefore PGA) was weaker on soft soil than on rock near the source of this magnitude 7.8 earthquake. Clearly the transition from linear to non-linear behaviour is strongly dependent on the soil strength [35], but we do not yet have enough data to model this over a range of soil types.

A further study illustrating non-linear effects is that of near-source accelerations by Campbell and Bozorgnia [31]. This showed that rock PGAs were greater than soil PGAs within about $15 \mathrm{~km}$ of the source regardless of magnitude. Our data set is not large enough to test this partly surprising finding, but, together with the results 


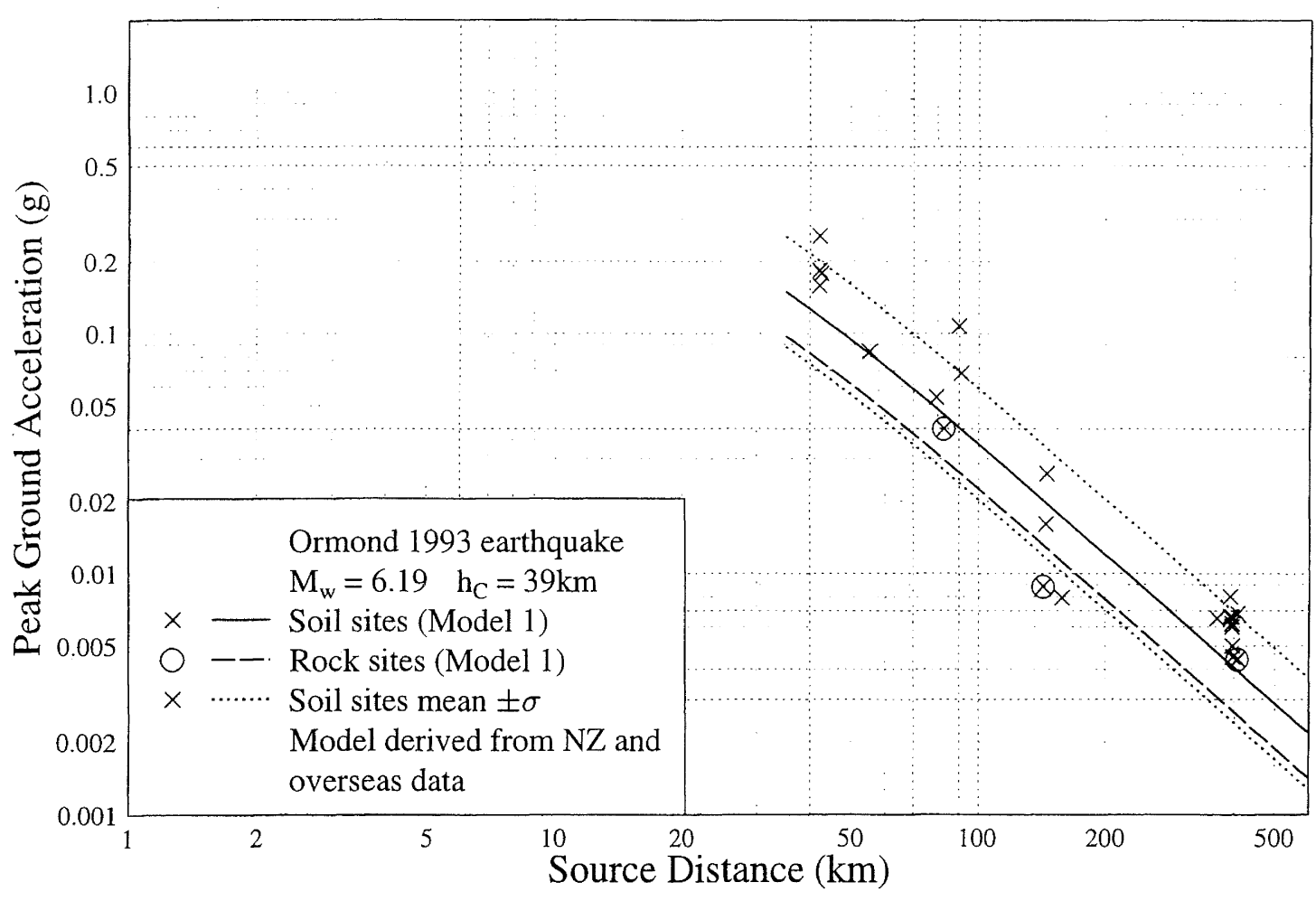

FIGURE 6 PGA data and Model l plotted for a relatively shallow slab event of depth $h_{C}=39 \mathrm{~km}$, the 1993 Ormond earthquake (event 45$)$. Note that the $(m-\sigma)$ curve for soil is nearly coincident with the mean curve for rock. Compare with the deep slab event in Figure 7.

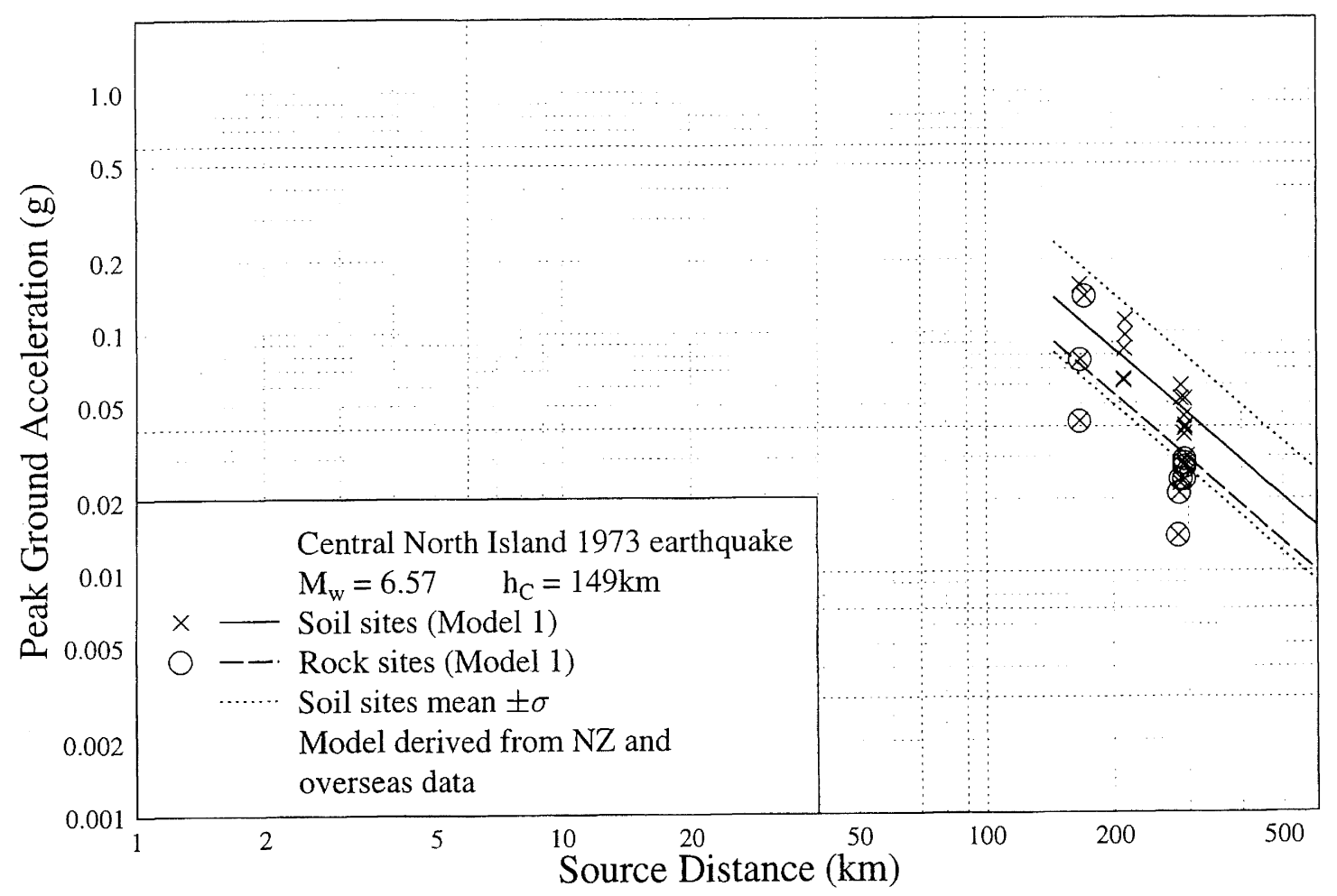

FIGURE 7 PGA data and Model 1 plotted for the deepest slab event of depth $h_{C}=149 \mathrm{~km}$, the 1973 Central North Island earthquake (event 7). 


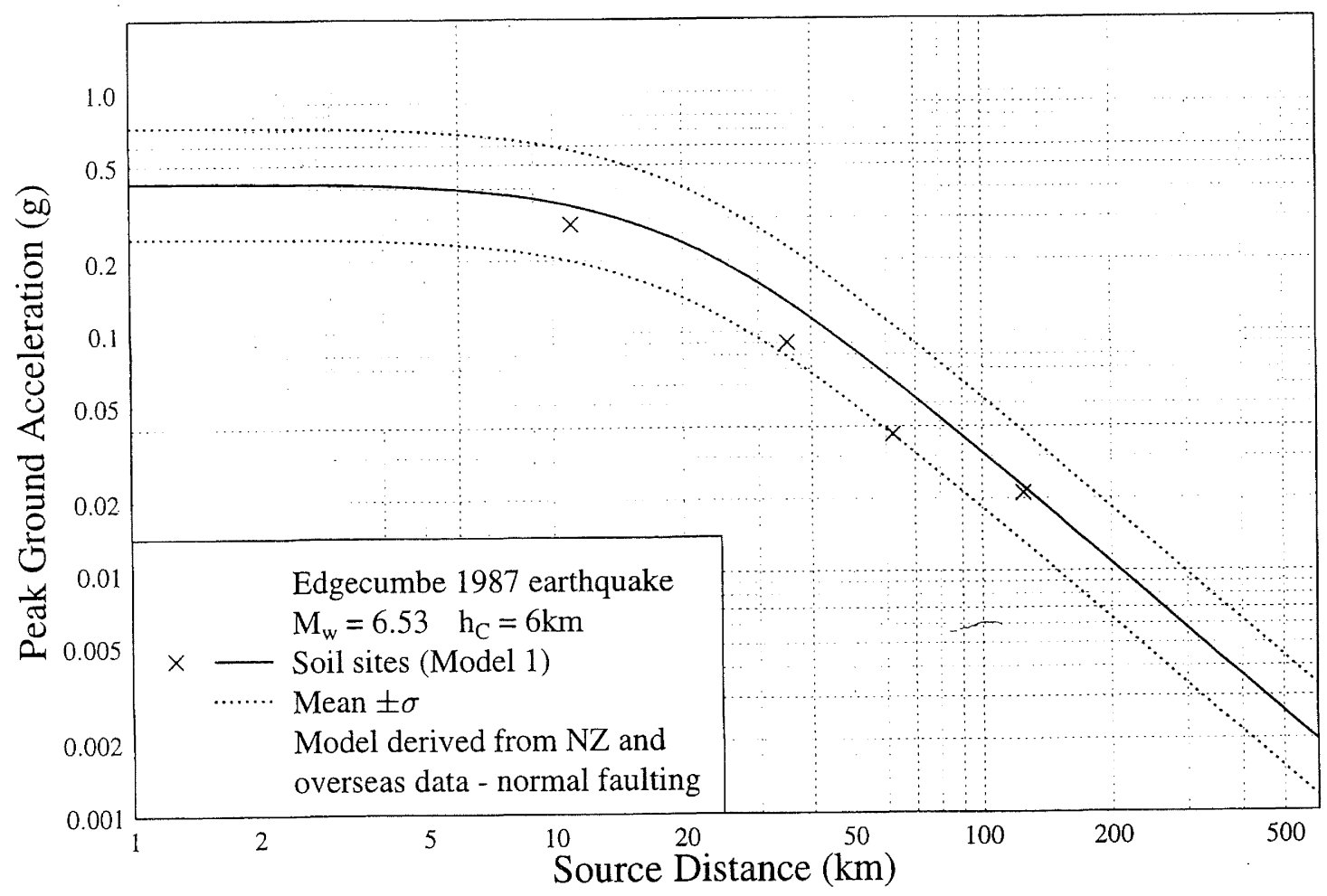

FIGURE 8 PGA data and Model 1 plotted for a normal faulting event of depth $h_{C}=6 \mathrm{~km}$, the 1987 Edgecumbe earthquake (event 23). The data all lie between the mean and $(m-\sigma)$ curves of the model.

of the two other studies noted above, it points to the inadequacy of our Model 1 in regard to weak soils near the source of large earthquakes. Models 1 and 2 and that of Campbell and Bozorgnia are used to model the largest event in the New Zealand data set (Inangahua), as plotted on Figures $9(\mathrm{a})$ and $9(\mathrm{~b})$. It is seen that the near-source data is fitted about the same by both Model 2 (Figure 9(b)) and the soil component of Model 1 (Figure 9(a)). In Figure 9(b) it is seen that Campbell and Bozorgnia's soft rock model gives stronger accelerations than the soil model at distances closer than $6 \mathrm{~km}$ from the source, and that their soil model underpredicts all of the Inangahua data.

\subsection{Effect of Overseas Data}

As discussed earlier, overseas data of near-source recordings were introduced for the sole purpose of controlling the model near the source. It was obviously desirable to do this without perturbing the model in the distance range of the New Zealand data. In Figure 10, we compare Model 1 (using all the Main Seismic Region data and overseas data) and the model derived using only the New Zealand data, and in which $d=0$ in equation (2). This plot demonstrates both the need for the near-source control and the fact that the overseas data has had negligible effect on the model for source distances greater than $20 \mathrm{~km}$. However, the near-source estimates from our models should still be treated with caution, because the magnitude dependence is assumed to be the same at all distances.

\subsection{Regional Effects in New Zealand}

The Central Volcanic Region (CVR) shown in Figure 1 is well recognised as having higher attenuation than other parts of New Zealand [e.g. Refs 39, 40]. In order to measure attenuation rates for PGAs within the CVR, it is of course necessary to find records generated by waves travelling wholly or largely within it. So far we have only nine such records. These records come from the three events identified in Table 1 (Nos 19, 42, 47) and located on Figure 1. The records were excluded from the data used for modelling the rest of the country. Their residuals from Model 1 are plotted on Figure 11, where it is seen that all these PGA values are less than their predicted values, with a mean residual value of -0.298 , a value greater than the standard error of 0.230 , and corresponding to a factor of 0.50 for PGA. These data were found to have a lower mean value than the rest of the data at a significance level of 0.01 . In addition Figure 1 shows that the residuals increase with distance, which is consistent with higher attenuation than in the Main Seismic Region.

The 1987 Edgecumbe earthquake (event 23) was located on the south-eastern boundary of the CVR (Figure 1), with its only strong-motion records being obtained to the south and east, i.e. having travel paths entirely outside of the CVR. As seen in Figure 8, these data conform to the model for that event using Model 1 , the mean residual being -0.123 , compared with the standard error of 0.23 .

Another region that has been thought $[41,42]$ to have a different attenuation pattern from the rest of New Zealand is Fiordland. In the present data set, there are four events located in that region, Nos. 10, 24, 25 and 44 in Table 1 and Figure 1. Note that these four events include the three tectonic types, crustal, interface and slab. The residuals of the 22 PGA data from those events with respect to Model 1 are plotted against source distance in Figure 12. The mean residual is 0.168 , and these records differ significantly from the other records in the data set at the 0.01 level. At present there is insufficient Fiordland data to explain 


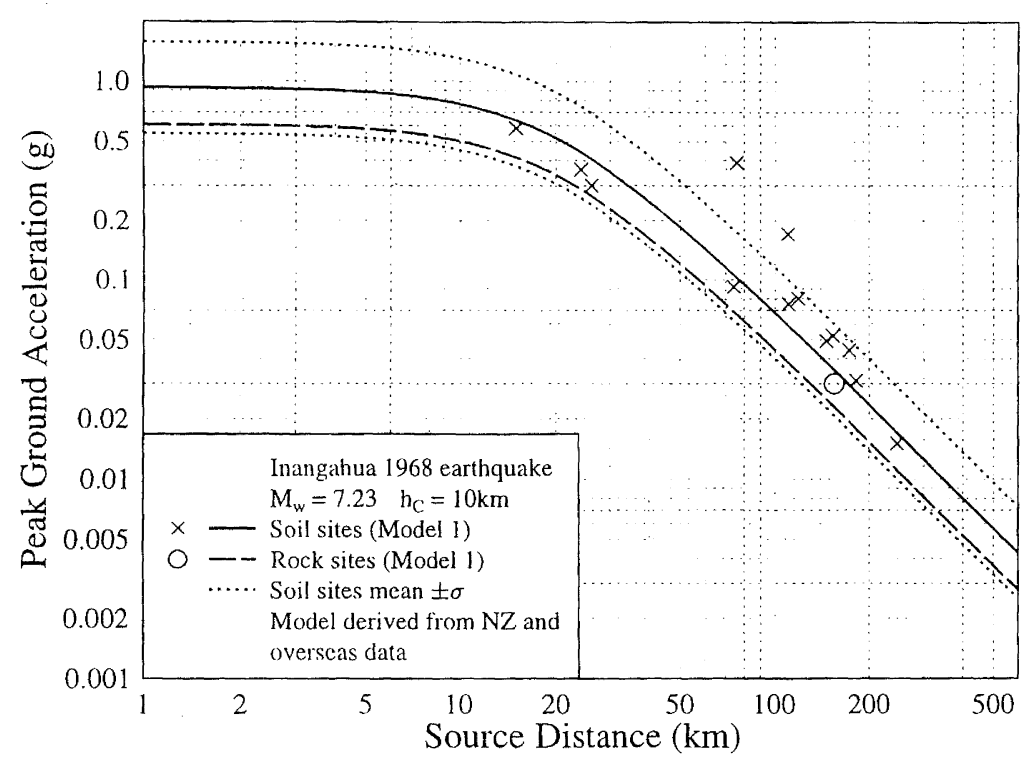

(a)

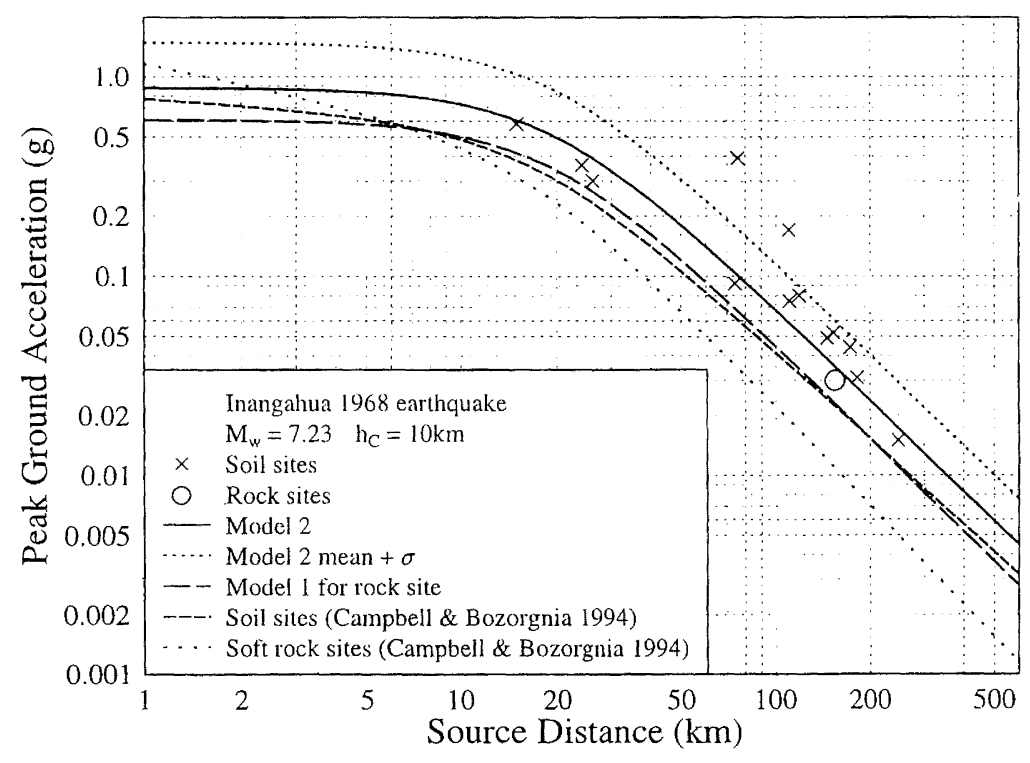

(b)

FIGURE 9 PGA data and rock and soil models for the largest magnitude event in the New Zealand data set, the reverse-faulting Inangahua 1968 earthquake (event 3): (a) Model 1; (b) Model 2 and an overseas model.

this finding, which may be due to source and/or directivity effects.

\subsection{Vertical versus Horizontal Accelerations}

Until recent years, little effort has been put into modelling vertical accelerations, and for design purposes it has been common to assume that the vertical PGA is typically two-thirds of the horizontal value, e.g. as in the 1994 Uniform Building Code of the USA. Using the present New Zealand data set, the ratio of the vertical PGA to the stronger horizontal component was found for each accelerograph record. These values were plotted against source distance, depth and $\mathrm{M}_{\mathrm{w}}$, and the mean value was found to be close to 0.5 over the full range of distance, depth and $M_{w}$, as shown for source distance in Figure 13. These results are based on the New Zealand data only; the very near-source overseas data have not been considered. The overall mean of this ratio was 0.48 and the standard deviation was 0.19 . Of the 317 observations of the ratio, only five are greater than 1.0, with the largest being 1.25. The mean plus one standard deviation value of the ratios for the New Zealand data is 0.65 , which is close to the two-thirds value noted above.

In a study of European PGAs, Ambraseys and Bommer [32] found that the mean ratio of peak vertical to peak horizontal 


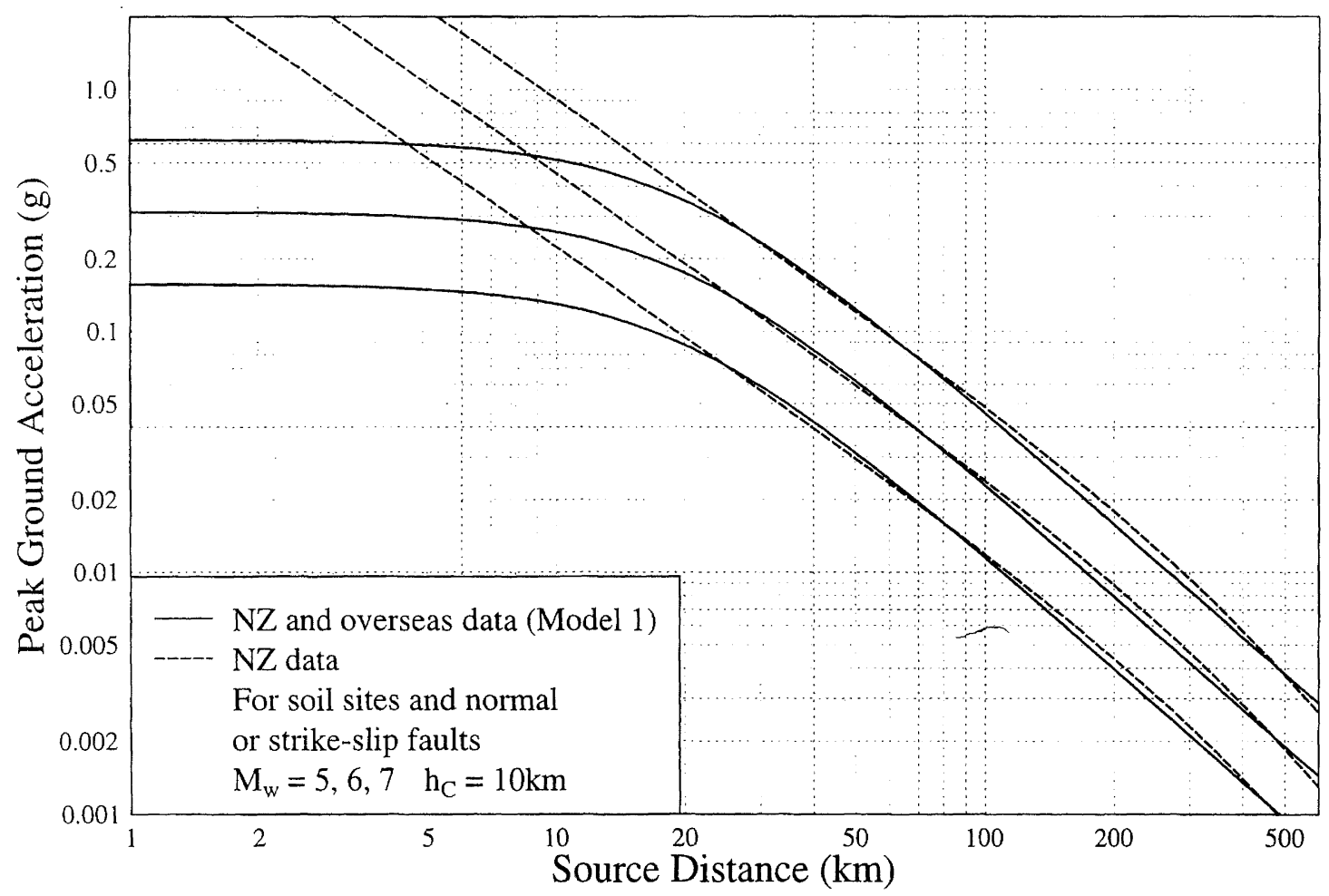

FIGURE 10 Comparison of attenuation models derived with and without overseas near-source data. The latter model was derived setting $d=0$ in equation (2). Note that the overseas data controls the model at short distances (less than about $20 \mathrm{~km}$ ), but has little effect at greater distances for which there is plentiful New Zealand data.

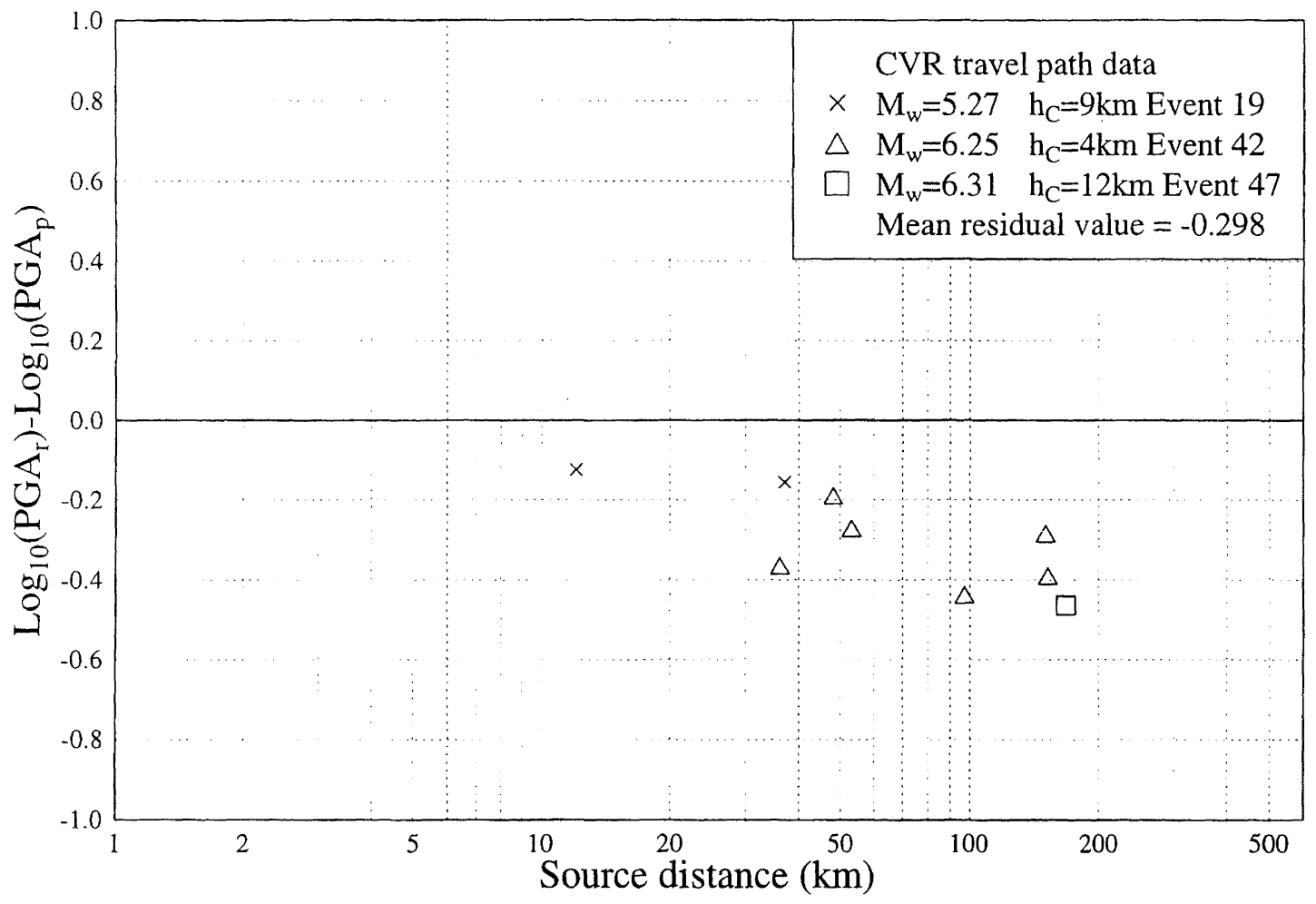

FIGURE 11 Plot of PGA residuals from Model 1 against source distance for three events having travel paths in the Central Volcanic Region, showing consistently large negative residuals. These data were not included in the regressions used to develop the attenuation relations. 
acceleration was 0.5 and was almost independent of magnitude and distance. Their horizontal acceleration was the larger of the two horizontal components. Thus our results are almost identical to theirs.

However, in the near-source region, the high-frequency content of vertical motions is often very strong, leading to peak ground accelerations that may exceed the horizontal values. In supplementing the mainly distant European data with world-wide near-source data, Ambraseys and Simpson [43] found that "very near the source of large thrust earthquakes the average value of the acceleration ratio $q$ may exceed one." Niazi and Bozorgnia [44] also found vertical accelerations exceeding horizontal accelerations in the very near-source region.

Ambraseys and Bommer, and some other researchers [e.g. 28, 45], have also produced attenuation expressions for vertical accelerations. As our vertical data set is relatively small (scratch plates do not measure vertical acceleration), and as the mean ratio of vertical to horizontal acceleration is so nearly constant with distance, we have not attempted to model the attenuation of vertical accelerations directly.

\subsection{Stronger Horizontal Component versus Mean Horizontal Component}

Some attenuation expressions have been based on the stronger of two horizontal components [e.g. Refs. 21, 22, 24, 25, 32, 33], while others have used the arithmetic mean [20] or the geometric mean [31] of the two horizontal components of PGA. In order to relate our attenuation models appropriately to those based on the mean value, we have modelled the relationship of these two acceleration measures for New Zealand data. The ratio of larger to the arithmetic mean of the horizontal component was calculated for the present New Zealand data set. These values were plotted against source distance, depth and $\mathrm{M}_{\mathrm{w}}$. It was found that the best fit mean value of this ratio was nearly constant over the full range of distance, depth and $\mathrm{M}_{\mathrm{w}}$. The overall mean of the ratios was 1.11 , i.e. the stronger component on average is $11 \%$ greater than the mean. This is similar to the $13 \%$ difference found by Campbell [20] from Western USA data.

\subsection{Effects of Structures on PGAs}

Some researchers (e.g. Ref. 23), exclude PGAs recorded in basements of taller buildings. In our dataset there are 33 records from basements of buildings with four storeys or more. Direct comparison of five pairs of records obtained from basements or ground floors of three high-rise buildings and nearby free-field sites indicated that PGAs from building basements or ground floors are significantly smaller than those of the free-field sites. However, contradictory to the direct comparisons, it was found that the mean residual of the basement or ground floor records from buildings of four storeys or more is not significantly different from zero at a significance level of 0.05 . Thus the study of effects of tall buildings for our data set is inconclusive. For the instances where we have pairs of free-field and basement records, only the free-field records have been included in our regression analyses. However, given the results of the residual analysis, other PGAs recorded in basements of taller buildings have been retained in our data set.

\subsection{Comparisons with other World Regions}

In previous studies [2-6] it was found that the attenuation of PGA in New Zealand appeared to be (i) similar to that given by models based on Japanese data, and (ii) different from that of Western USA based modeis and those based on European data. It is appropriate to make new comparisons based on the more extensive New Zealand database now available and recent models from these selected world regions.

For a comparison between Japan and New Zealand, we compare our Model 5 with the 1990 model of Fukushima and Tanaka [24] and the 1995 model of Molas and Yamazaki [33]. These attenuation expressions were used to model the 1995 Hyogo-ken Nanbu (Kobe) earthquake of $M_{w} 6.9$ and $h_{C}=10 \mathrm{~km}$. As the two Japanese models do not differentiate between focal mechanisms or ground classes, we used our Model 5 to make as direct a comparison as possible. A large set of PGA data for this earthquake is plotted in Figure 14. As can be seen in Figure 14, our New Zealand model is very similar to that of Fukushima and Tanaka and both fit the data well from the shortest source distance of $3 \mathrm{~km}$ to the furthest of almost $300 \mathrm{~km}$. The Molas and Yamazaki model is not as close to ours as that of Fukushima and Tanaka, and suffers from having no near-source control.

Next a comparison was made of the 1991 attenuation model of Ambraseys and Bommer [32] for Europe, and of the 1981 model of Joyner and Boore [21] for the Western USA. These models were made as directly comparable as possible by using a depth of $\mathrm{h}_{\mathrm{C}}=7 \mathrm{~km}$ in the New Zealand model (corresponding closely to the values of the added "depth" parameter used in both of those models), the models being for a mixture of mechanisms and ground classes in all cases. For $\mathrm{M}_{\mathrm{w}}=7$, it was found (Figure 15) that over the distance range of about $20-100 \mathrm{~km}$ the New Zealand Model 5 predicts mean PGAs about $40-80 \%$ stronger than those for Europe and for those of Joyner and Boore's 1981 model. This difference is consistent with previous findings [2-6]. The difference between the New Zealand model and the other two decreases with decreasing magnitude. but is still substantial at $M_{w}=6$. We note that Joyner and Boore's expression is not valid for distances greater than $100 \mathrm{~km}$.

We also compared our Model 4 (for soil) with two more recent (1993 and 1994) models for the western USA, i.e. those of Boore et al [22] and of Campbell and Bozorgnia [31]. The three models are plotted in Figure 15 for an event of $\mathrm{M}_{\mathrm{w}} 7.0$ with $\mathrm{h}_{\mathrm{C}}=7 \mathrm{~km}$. The Campbell and Bozorgnia model has also been discussed in Section 7.6 above in relation to Figure 9. Although there are some magnitude and distance combinations for which any two of these models predict similar PGA values, the dependence of these models on magnitude and distance is very different. If nothing else, these comparisons underline the need for the development of a robust model based largely on New Zealand data.

As well as the comparisons shown in Figures 9(b), 14 and 15, several models have been evaluated by performing residual analyses for the New Zealand data with respect to them. Results of some of these residual analyses are summarised in Figure 16. Only the New Zealand data, or subsets of the New Zealand data as indicated in the key to Figure 16, have been used in the residual analyses. Figures 16(a) and (c) show the root-mean-square (RMS) values of the residuals, that is the observed minus predicted values of $\log _{10} \mathrm{PGA}$, as a function of magnitude $\mathrm{M}_{\mathrm{W}}$ and horizontal distance for various models. Figures 16(b) and (d) show plots of the mean residual factor, that is the geometric mean ratio between 


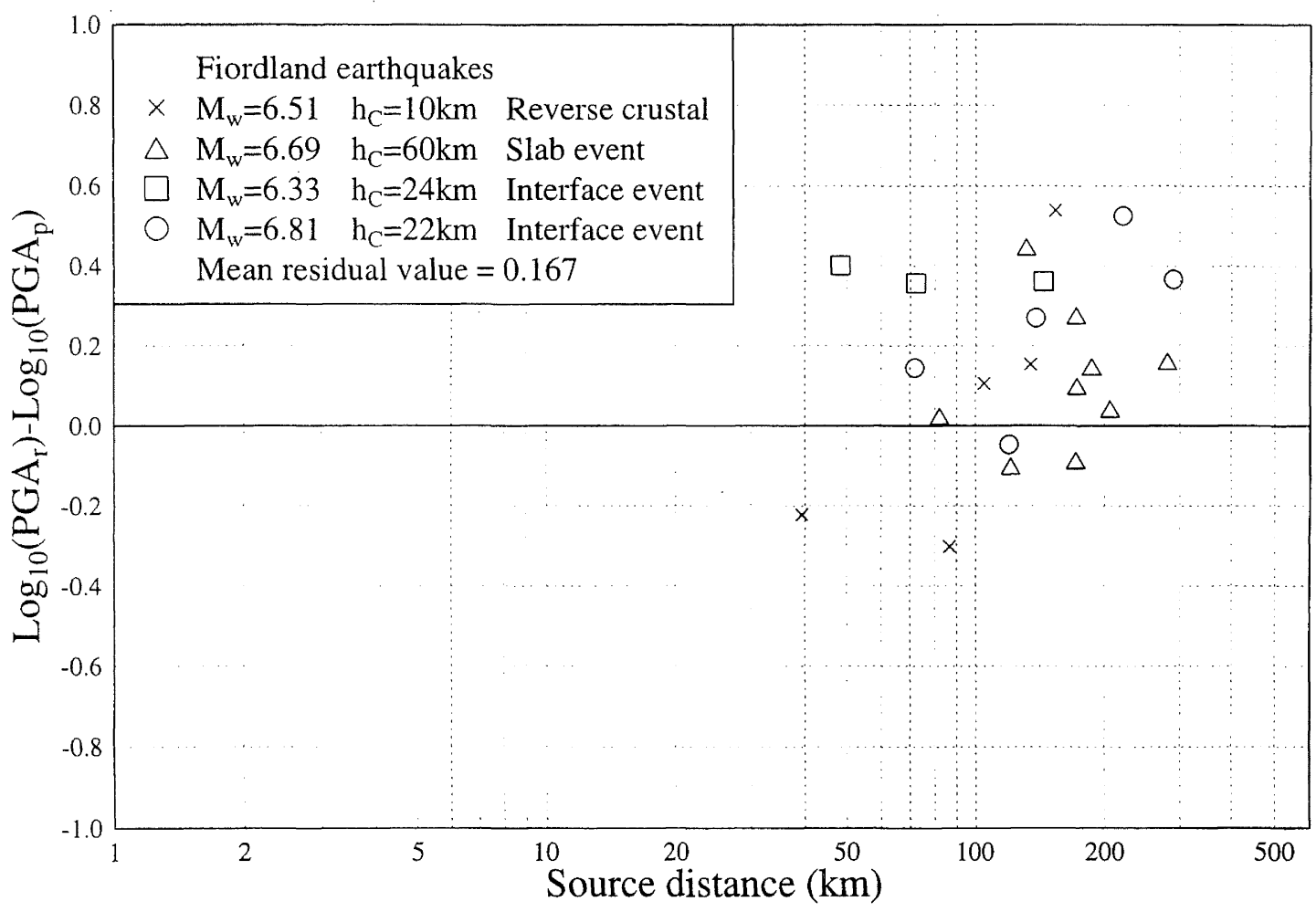

FIGURE 12 Plot of PGA residuals from Model 1 against source distance for four events from Fiordland, showing residuals with a mean positive value of 0.168 , which is different from zero at the 0.01 significance level.

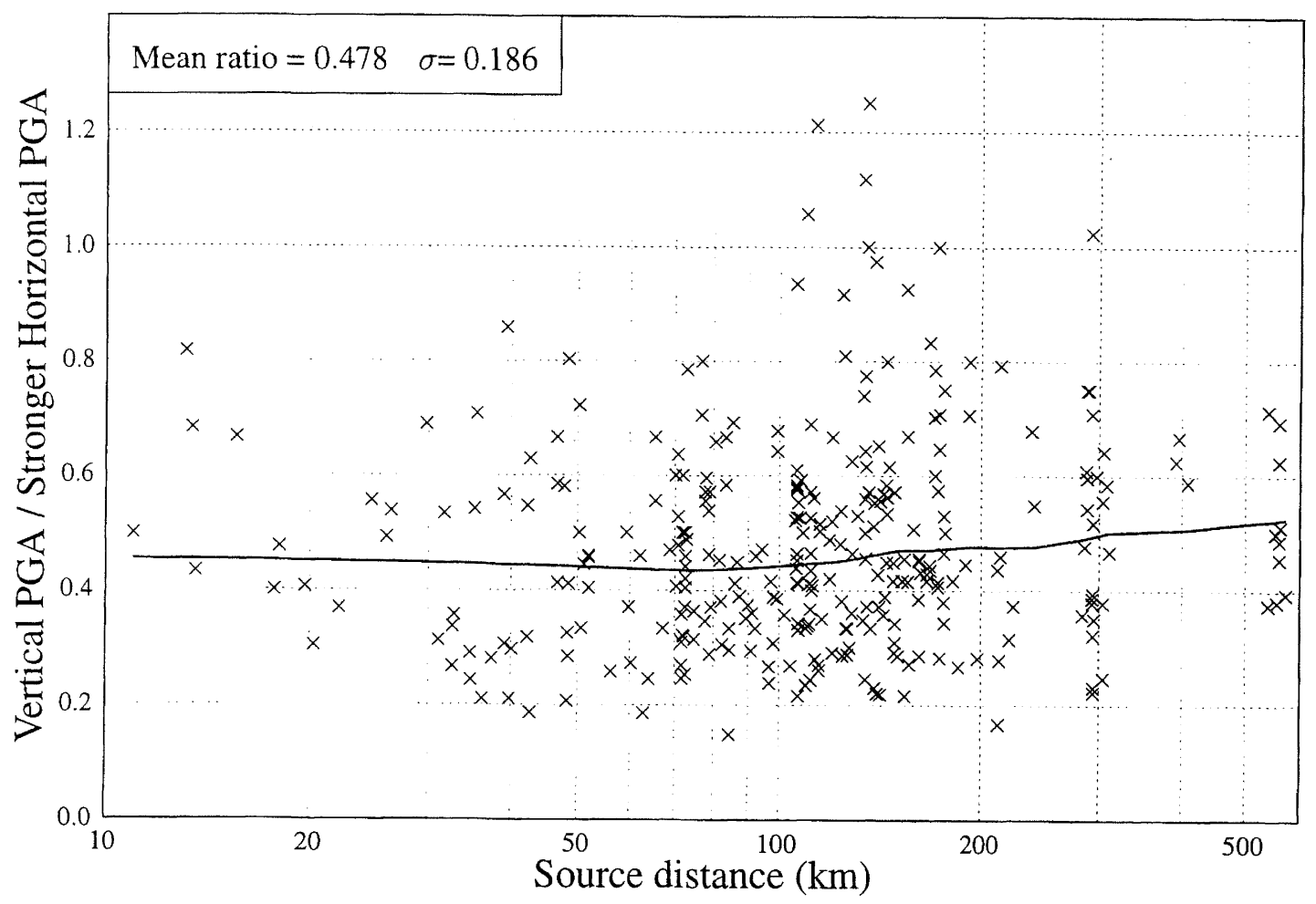

FIGURE 13 Plot of ratio of the PGAs of the vertical to the stronger horizontal component, against source distance. The mean ratio of 0.48 is almost insensitive to distance over the range of the New Zealand data, as shown by the robust smooth line fitted by a local regression technique. No overseas near-source data is included. 


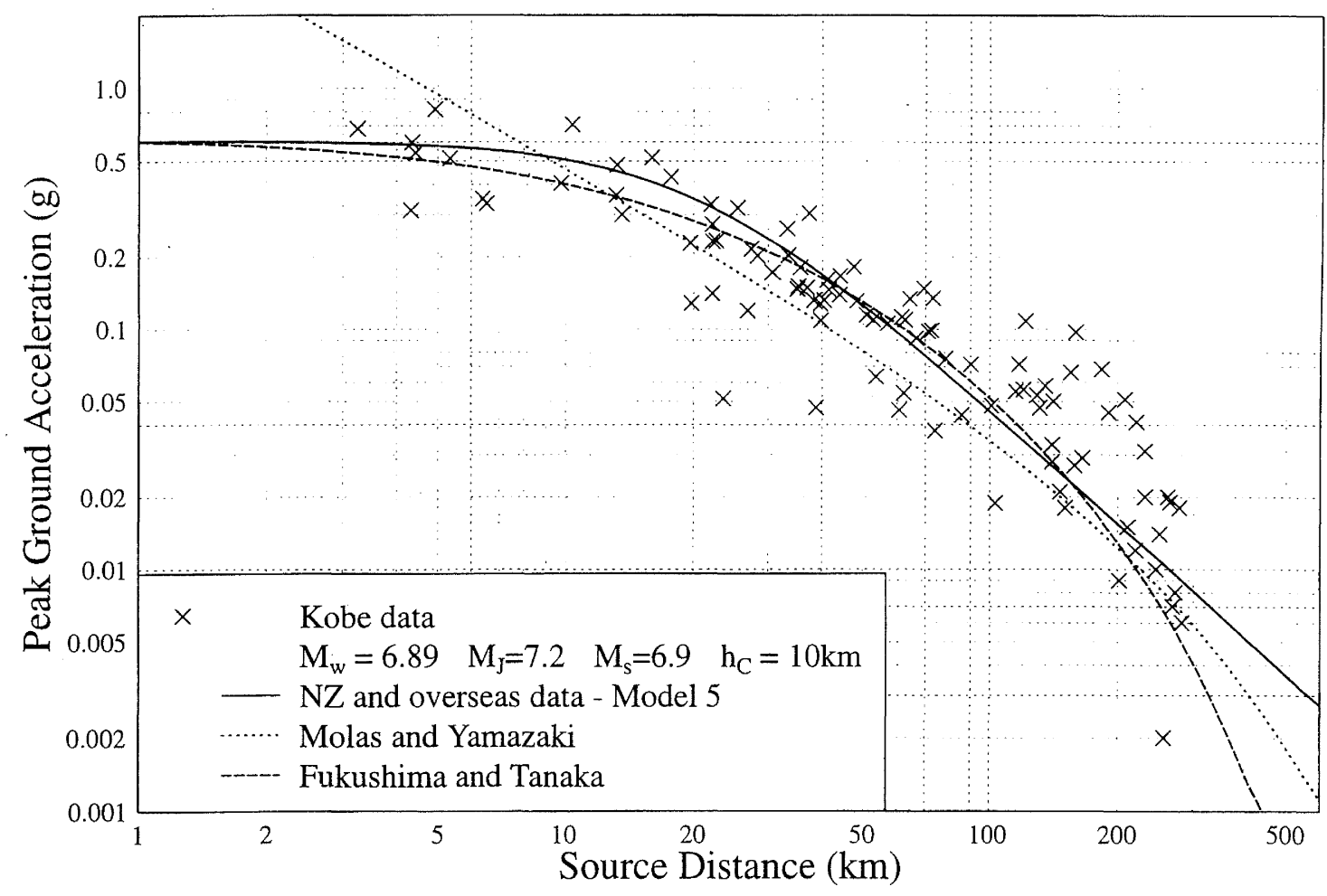

FIGURE 14 PGA data from the 1995 Hyogo-ken Nanbu (Kobe) earthquake, plotted against Model 5 from the present study and two Japanese models, using appropriate magnitude scales. Model 5 is used because source and site effect terms are not included in the Japanese models.

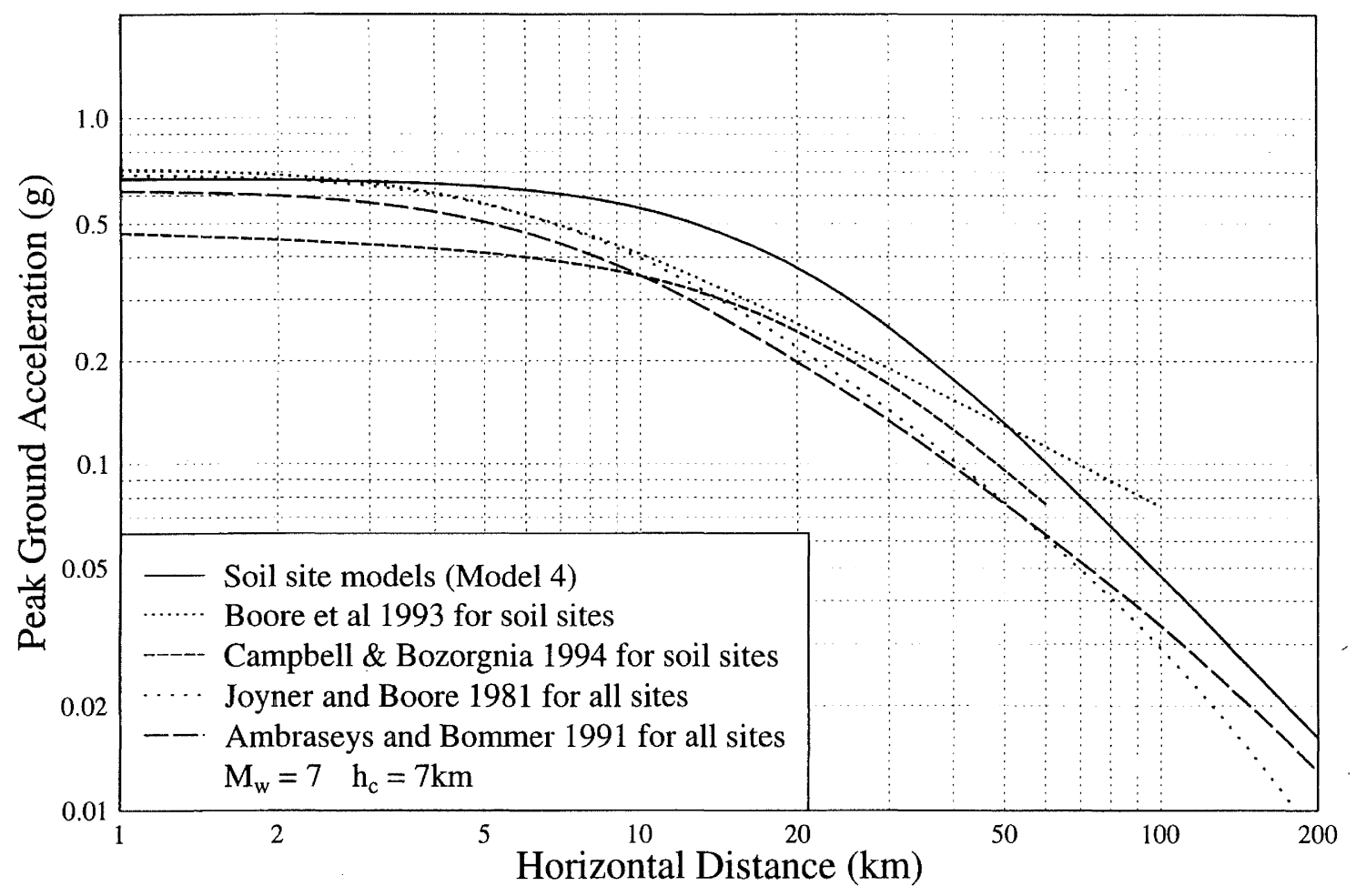

FIGURE 15 Comparison of attenuation models at $M_{W} 7.0$ for soil sites, from (1) the present study (Model 4), (2) Boore et al (1993), (3) Campbell and Bozorgnia (1994), Joyner and Boore (1981) and Ambraseys and Bommer (1991). 
the model prediction and observed values of PGA as given by $10^{\text {-mean residual of } \log _{10} \mathrm{PGA}}$. The data has been divided into magnitude bands of half a unit centred on the plotted magnitude, and distance classes of 10-30 km, 30-60 km, 60-100 km, 100-200 km, 200-300 $\mathrm{km}$ and $300-500 \mathrm{~km}$. The different depth, tectonic types and distance ranges selected for the comparisons with the various models reflect the different ranges of data used in deriving them.

As the model parameters were estimated by minimizing the RMS residual across a similar dataset ( with the addition of the overseas near-source data), it is not surprising that the New Zealand model gives the smallest RMS residuals for most classes. A feature of interest is that the RMS residuals for the New Zealand model are fairly constant for the various magnitude and distance classes. Some overseas studies e.g. $[28,29]$ have suggested that the RMS residuals reduce for larger magnitudes. As the largest PGA values are associated with the largest magnitudes, a reduced residual decreases the probability of very high PGA estimates in hazard analyses. The RMS residual value is a very important parameter affecting PGA estimates for long return periods. The New Zealand model shows no marked trend of reduced RMS residuals with increasing magnitude when all the New Zealand data is considered (Figure 16(a)). When only the crustal data are considered, the 1993 Boore et al., 1991 Ambraseys and Bommer and 1994 Campbell and Bozorgnia models show such a trend, except in the magnitude 7.0-7.5 range. The reductions are most marked between the 5.0-5.5 and 5.5-6.0 magnitude ranges. The
New Zealand model also shows a suggestion of decreasing RMS residuals with increasing magnitude when only crustal data is considered (not plotted), but to a lesser extent than for the overseas models. The RMS residual for crustal data for the New Zealand model decreases from 0.282 in the magnitude 5.0-5.25 range to 0.223 in the magnitude 7.0-7.5 range, but includes a jump back to 0.282 in the magnitude $6.6-7.0$ range.

After the New Zealand model, the next lowest RMS residuals are generally given by the Fukushima and Tanaka model from Japan, except for an anomaly in the magnitude $6.5-7.0$ class. The overall RMS residual value for this model is 0.269 , the lowest of the overseas models, compared to 0.234 for the New Zealand model. The Fukushima and Tanaka model also has a mean residual factor very close to unity, with a value of 1.05 , another indication of a good fit to the data. The comparison for this model includes some interface and slab data in that it included events with centroid depths to $50 \mathrm{~km}$, and distances up to $300 \mathrm{~km}$, while the comparisons for the other models were for crustal data only, and to shorter distances, as indicated in the key of Figure 16.

The 1996 Abrahamson and Silva model also gives a good fit to the New Zealand crustal data, provided distances beyond $200 \mathrm{~km}$ are excluded, where the matches become very poor. Within this distance range, the RMS residual of the Abrahamson and Silva model for the New Zealand crustal data was 0.274 , with a mean residual factor of 1.024

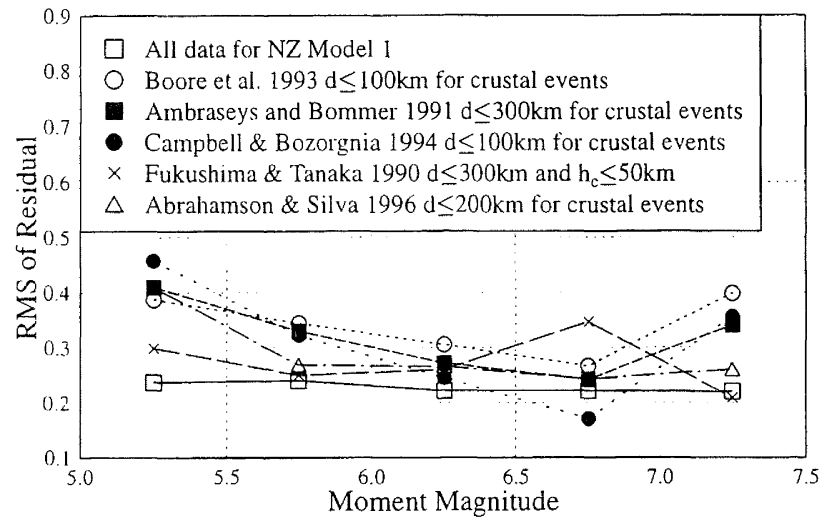

(a)

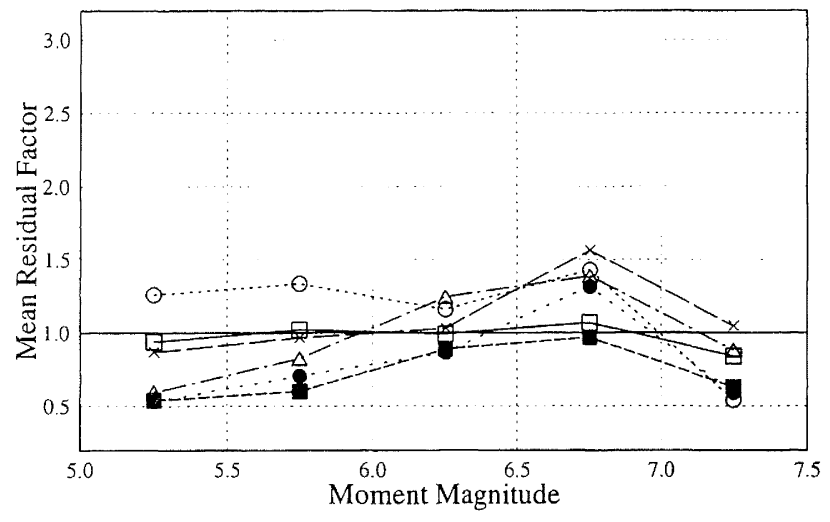

(b)

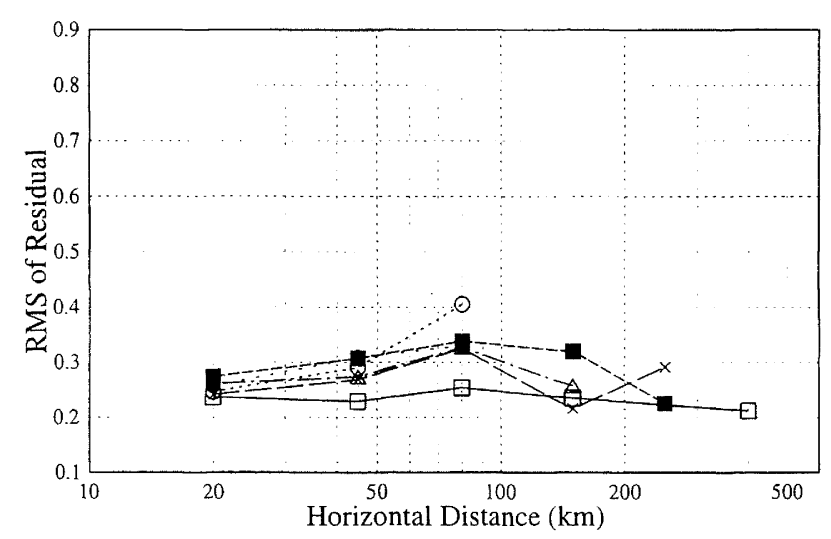

(c)

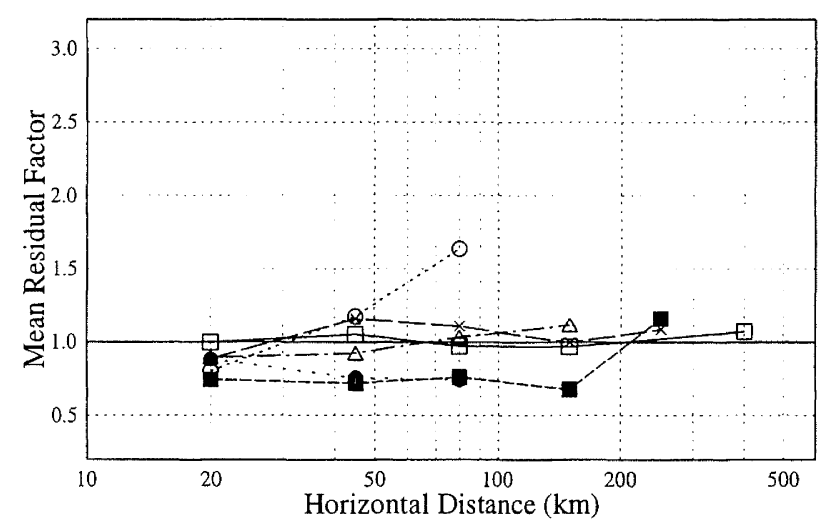

(d)

FIGURE 16 Comparison of residuals of subsets of New Zealand data for various models. Good matches are indicated by low RMS residuals, and a mean residual factor (MRF) near 1.0. The MRF is the geometric mean of the predicted PGA/recorded PGA. 
The 1993 Boore et al. model substantially overpredicts the New Zealand data on average, with a mean residual factor of 1.23 . This indicates considerable changes in estimates of Californian PGAs as more data has become available, in that the 1981 Joyner and Boore model generally underpredicts New Zealand data. The differences in the fits of the Boore et al., Campbell \& Bozorgnia and Abrahamson \& Silva models show the dependence of the predictions on the form of model, not just the region that provides the data on which it is based, and hence the difficulty in comparing estimates for different regions.

Formal statistical testing has been performed to test whether the New Zealand data are predicted by the overseas attenuation models.

The hypothesis that a mean residual of zero is given by the Fukushima and Tanaka model cannot be rejected at the $5 \%$ significance level, but the RMS residual of 0.269 for the data to a centroid depth of $50 \mathrm{~km}$ and distance of $300 \mathrm{~km}$ is not consistent with the standard deviation of 0.201 for the model. The Fukushima \& Tanaka model exhibits magnitude saturation at short distances which is not included in the New Zealand model, so the behaviour of the two models differs in the near-source region at large magnitudes for which there is no New Zealand data as yet.

The Abrahamson and Silva model also gives a mean residual that does not differ from zero at the $5 \%$ significance level, when only crustal data at distances less than $200 \mathrm{~km}$ is considered. This fit of New Zealand data by a model developed from mainly US data is contradictory to the results of our earlier studies. Previously, we have not restricted our attention to only crustal data. Also, the Abrahamson and Silva model predicts rather different PGAs than do some earlier US models. The change in our conclusions perhaps reflects a combination of comparing only data from events of the same tectonic class, and a shift in US predictions caused by data from recent earthquakes.

Hypotheses that the Boore et al., Campbell \& Bozorgnia and Ambraseys \& Bommer models accurately predict New Zealand PGAs, i.e., that they give mean residuals of zero for New Zealand data, can be rejected.

\subsection{CONCLUSIONS}

From the above study, the following conclusions have been drawn:

1. Attenuation expressions have been derived for New Zealand peak ground accelerations in terms of magnitude $M_{\mathrm{w}}$ and source distance, which allow for the influence of depth, focal mechanism, tectonic type and ground class. The expressions are not recommended for use for earthquakes with $M_{w}>7.4$ (i.e. beyond the magnitude limit of the data).

2. All of the models were found to be reasonably robust in statistical terms. The weakest aspect is differentiating between soil and rock PGAs within 10-15 km of the source. More near-source data, particularly from rock sites, is needed to resolve this problem.
3. Distance is accounted for as the logarithm of a function of the shortest distance from site to source. An anelastic attenuation term, $\mathrm{Cr}$, was also considered, but was found to be not statistically significant, or in some cases was rejected because the constant term $\mathrm{C}$ became positive.

4. Depth is accounted for explicitly as a linear function of centroid depth, and the effect of depth is found to be large, e.g. events with depths of $150 \mathrm{~km}$ cause predicted mean PGAs 7.4 times those of events with depths of $10 \mathrm{~km}$, all other factors held equal.

5. Ground classes were found to separate into two groups which produce PGAs different from each other, i.e. rock and soil, where rock sites comprised those with either surface rock or bedrock overlain by $\leq 3 \mathrm{~m}$ of soil, and soil sites comprised all other types of site. The surface soil layer thickness probably could be increased to $10 \mathrm{~m}$ with little effect on the model. PGAs from soil sites were found to be 53 percent stronger on average than PGAs from rock sites.

6. Crustal events with predominantly reverse faulting focal mechanisms were found to cause predicted mean PGAs 28 percent greater than those of normal or strike-slip crustal events for the same magnitude, depth and distance. The mechanism term was taken as a constant, with no consideration of the possibility that it could vary with magnitude or distance.

7. Interface earthquakes, which have predominantly reverse mechanisms, were found to produce PGAs that are on average 0.59 times those of crustal reverse events when other parameters are the same, and 0.75 times those of crustal normal or strike-slip events. Slab events were found to produce PGAs similar to those of crustal normal and strike-slip events, with the mechanism term insignificant for slab events (with other parameters held the same).

8. Near-source modelling of PGAs was controlled by supplementing the New Zealand data with near-source data from overseas earthquakes. This was done without significantly perturbing the modelling of attenuation for source distances greater than $20 \mathrm{~km}$. While the nearsource modelling appears to be reasonable overall, the predictions for both soil and rock sites individually appear to be unsatisfactory for large earthquakes, i.e. for $M_{w}$ greater than about 7 . In this range, the predicted PGAs are too large for weaker soils and too small for rock. More data is needed to resolve this problem. The model does not include the possibility of saturation of PGAs with magnitude, i.e. the variation with magnitude was taken to be the same for all distances.

9. The PGA data for travel paths within the Central Volcanic Region were found to be statistically significantly different from that for the rest of New Zealand at the 0.01 level, supporting the thesis that attenuation rates are higher in the CVR than elsewhere. The mean residual for the CVR data corresponds to a factor of 0.50 for PGA. 
10. It was found that the PGA data from the four Fiordland earthquakes differed significantly from data for the rest of the country, at the 0.01 level. This data suggests that PGAs in Fiordland are higher for a given set of parameter values than elsewhere in the country.

11. Vertical PGAs were found on average to be 0.48 times the PGAs of the stronger horizontal component, when considered on a record-by-record basis. This is very similar to the ratio of 0.5 found for European earthquakes by Ambraseys and Bommer [32]. No data with source-tosite distance $<11 \mathrm{~km}$ was considered in this part of the study.

12. The stronger horizontal component of PGA was found to be on average 11 percent larger than the mean of the two horizontal components, when considered on a record-byrecord basis. This is close to the value of 13 percent found for Western USA data by Campbell [20].

13. The New Zealand attenuation model is very similar to that of Fukushima and Tanaka for Japan over a distance range 0-200 km for events of centroid depth up to about $50 \mathrm{~km}$ and magnitude up to 7.4 .

14. The 1996 Abrahamson and Silva model predicts New Zealand crustal event PGAs well for distances up to $200 \mathrm{~km}$.

15. The 1993 Boore et al. model substantially overpredicts New Zealand crustal event PGAs, by $23 \%$ on average.

16. The 1981 Joyner and Boore, 1991 Ambraseys and Bommer, and the 1994 Campbell and Bozorgnia models all substantially underpredict the PGAs from New Zealand crustal earthquakes.

\section{ACKNOWLEDGEMENTS}

The authors are grateful for general advice received from N.N. Ambraseys of Imperial College, London, and to our colleagues D.A. Rhoades for advice on statistical testing, T.H. Webb for advice on earthquake source parameters, and W. J. Cousins for help in preparing the New Zealand PGA data file and assistance with some of the graphics. N. Abrahamson and P. Somerville provided valuable pointers relating to the inclusion of tectonic type, in a related study supported financially by ECNZ. We also appreciate the thoughtful in-house reviews of the manuscript by our colleagues P.N. Davenport and W. J. Cousins. This study was funded by FRST over a number of years, the most recent being under Contract No C05405. Invaluable financial support for digital accelerographs over the past seven years has been received from the Earthquake Commission; this has greatly speeded up the acquisition of sufficient data to make this study possible.

\section{REFERENCES}

1. Matuschka, T. (1980) Assessment of seismic hazard in New Zealand, Report No. 222, Department of Civil Engineering, University of Auckland.
2. Dowrick, D.J. and S. Sritharan (1993) Attenuation of peak ground accelerations in some recent New Zealand earthquakes, Bulletin NZ National Society for Earthquake Engineering, 26, 3-13.

3. Dowrick, D.J., and S. Sritharan (1993) Peak ground accelerations recorded in the 1968 Inangahua earthquake and some attenuation implications, Bulletin NZ National Society for Earthquake Engineering, 26, 349-355.

4. McVerry, G.H., D.J. Dowrick, S.Sritharan, W.J. Cousins, and T.E. Porritt (1993) Attenuation of peak ground acceleration in New Zealand, Proc. Intl. Workshop on Strong Motion Data, Menlo Park, USA, Vol. 2, 23-38.

5. McVerry, G.H., D.J. Dowrick, J.X. Zhao (1995) Attenuation of peak ground accelerations in New Zealand, Proc. Pacific Conference on Earthquake Engineering, Melbourne, Vol. 3, 287-292.

6. Iai, S., and Y. Matsunaga (1993) Comparison of attenuation relations and response spectra for various regions in the world, Proc. Intl. Workshop on Strong Motion Data, Menlo Park, USA, Vol. 1, 17-37.

7. Dowrick, D.J., and D.A. Rhoades, Magnitudes of New Zealand earthquakes (in prep.)

8. Anderson, H., T. Webb, and J. Jackson (1993) Focal mechanisms of large earthquakes in the South Island of New Zealand: implications for the accommodation of Pacific-Australia plate motion, Geophysical Journal International, 115, 1032-1054.

9. Webb, T.H., and H. Anderson Focal mechanisms of large earthquakes in the North Island of New Zealand: strain partitioning at an oblique active margin (in preparation).

10. Webb, T.H., IGNS, Wellington, pers. comm.

11. Dziewonski, A.M. et al, Centroid moment tensor solutions .... Physics of the Earth and Planetary Interiors, various issues.

12. Webb, T.H., IGNS, Wellington, pers. comm., re focal mechanisms and seismic moments of events Nos 44, 46 and 51 .

13. Robinson, R. (1994) Shallow subduction tectonics and fault interaction: The Weber, New Zealand, earthquake sequence of 1990-1992, Journal of Geophysical Research, 99, B5, 9663-9679.

14. Luo, X. (1992) Subduction interface and crustal structure in the Cape Palliser region, North Island, New Zealand, from observations of Cape Palliser earthquakes, New Zealand Journal of Geology and Geophysics, 35, 491-499.

15. Reyners, M., P. McGinty, J. Ansell, and B. Ferris (1997) Movement at the plate interface in Southern Hawke's Bay; the Tikokino earthquake of 11 April 1993 (in prep.) 
16. McVerry, G.H., S.B. Hodder, R.T. Hefford and A. J. Heine (1984) Records of engineering significance from the New Zealand strong-motion network, Proc. Eighth World Conference on Earthquake Engineering, San Francisco, II, 199-206

17. NZS4203:1992 Code of practice for general structural design and design loadings for buildings, Standards New Zealand, Wellington

18. Cousins, W. J., N. D. Perrin, G. H. McVerry, R. J. Hefford and T. E. Porritt (1996) Ground conditions at strong motion recording sites in New Zealand, Institute of Geological and Nuclear Sciences, Science Report 96/33, Lower Hutt, New Zealand.

19. Otsuka, H., H. Iwasaki and R. Isoyama (1993) Attenuation characteristics of near-source motions, Proc. Intl. Workshop on Strong Motion Data, Menlo Park, California, Vol. 2, 83-98.

20. Campbell, K.W. (1981) Near-source attenuation of peak horizontal acceleration, Bulletin Seism. Soc. of America, 71, 2039-2070

21. Joyner, W. B., and D.M. Boore (1981) Peak horizontal acceleration and velocity from strong-motion records including records from the 1979 Imperial Valley, California, earthquake, Bulletin Seism. Soc. of America, 71, 2011-2038

22. Boore, D. M., W.B. Joyner, and T.E. Fumal (1993) Estimation of response spectra and peak accelerations from Western North American earthquakes: an interim report, Part 1, Open-File Report 93-509, U.S. Geological Survey, Menlo Park.

23. Boore, D. M., W. B. Joyner, and T. E. Fumal (1994) Estimation of response spectra and peak accelerations from Western North American earthquakes: an interim report, Part 2, Open-File Report 94-127, U.S. Geological Survey, Menlo Park.

24. Fukushima, Y., and T. Tanaka (1990) A new attenuation relation for peak horizontal acceleration of strong earthquake ground motion in Japan, Bulletin Seism. Soc. of America, 80, 757-783.

25. Crouse, C.B. (1991) Ground-motion attenuation equations for earthquakes on the Cascadia subduction zone, Earthquake Spectra, 7(2), 201-236.

26. Idriss, I. M. (1985) Evaluating seismic risk in engineering practice, Proc. 11th Intl. Conf. on Soil Mechanics and Foundation Engineering, San Francisco, Vol 1, 225-360.

27. Idriss I. M. (1991) Selection of earthquake ground motions at rock sites, Report prepared for the Structures Division, Building and Fire Research Laboratory, National Institute of Standards and Technology, Department of Civil Engineering, University of California, Davis.
28. Abrahamson, N., and W. Silva (1996) Empirical response spectra attenuation relations for shallow crustal earthquakes, Seismological Research Letters, 68 (1), 94117.

29. Youngs, R. R., N. Abrahamson, F. Makdisi, and K. Sadigh (1995) Magnitude-dependent variance of peak ground acceleration, Bulletin Seism. Soc. of America 85(4), 1161-1176.

30. Donovan, N. C. and A. E. Bornstein (1978) Uncertainties in seismic risk procedures, Journal of the Geotechnical Division, ASCE, 104, 869-887.

31. Campbell, K.W., and Y. Bozorgnia (1994) Near-source attenuation of peak horizontal acceleration from worldwide accelerograms recorded form 1957 to 1993, Proc. Fifth U.S. National Conference on Earthquake Engineering, Chicago.

32. Ambraseys, N.N., and J.J. Bommer (1991) The attenuation of ground accelerations in Europe, Earthquake Engineering and Structural Dynamics, 20, 1179-1202.

33. Molas, G.L., and F. Yamazaki (1995) Attenuation of earthquake ground motion in Japan including deep focus events, Bulletin Seism. Soc. of America, 85, 1343-1358.

34. Dowrick, D.J. (1991) Attenuation of Modified Mercalli intensity in New Zealand earthquakes, Earthquake Engineering and Structural Dynamics, 21, 181-196.

35. Ambraseys, N.N. (1973) Dynamics and response of foundation materials in epicentral regions of strong earthquakes, Proc. 5th World Conf. on Earthq. Eng., Rome, 1, CXXVI-CXLVIII.

36. Idriss, I.M. (1990) Response of soft soil sites during earthquakes, Proc. Memorial Symp. to honor Professor Harry Bolton Seed, Berkeley California, Vol II, 273-289.

37. Dowrick, D.J., D.A. Rhoades, J. Babor and R.D. Beetham (1995) Damage ratios for houses and microzoning effects in Napier in the magnitude 7.8 Hawke's Bay, New Zealand earthquake of 1931, Bulletin NZ National Soc. for Earthq. Engineering, 28, 134-145.

38. Idriss, I. M. (1991) Earthquake ground motions at soft soil sites, Proc. Second International Conference on Recent Advances in Geotechnical Earthquake Engineering and Soil Dynamics, St Louis, Missouri, Vol. III, 2265-2272.

39. Haines, A. J. (1981) A local magnitude scale for New Zealand earthquakes, Bulletin Seism. Soc. of America, 71(1), 275-294.

40. Cousins, W.J. Use of seismograph data for PGA attenuation modelling (in preparation).

41. Smith, W.D. (1978) Spatial distribution of felt intensities for New Zealand earthquakes, NZ Journal Geology and Geophysics, 21, 293-311. 
42. Smith, W. D. (1995) A development in the modelling of far-field intensities for New Zealand earthquakes, Bulletin N.Z. Natl. Soc. for Earthquake Engineering, 28(3), 196217.

43. Ambraseys, N. N., and K.A. Simpson (1996) Prediction of vertical response spectra in Europe, Earthquake Engineering and Structural Dynamics, 25, 401-412.

44. Niazi, M., and Y. Bozorgnia (1992) Behaviour of nearsource vertical and horizontal response spectra at SMART-l array, Earthquake Engineering and Structural Dynamics, 21, 37-50

45. Abrahamson, N.A., and J.J. Litehiser (1989) Attenuation of vertical peak acceleration, Bulletin Seism. Soc. of America, 79, 549-569.

46. Anderson, H., et al., (1994) The Inangahua, New Zealand, earthquake: an integrated geological, geodetic and seismological source model, NZ Journal Geology and Geophysics, 37(1), 59-86. 